\title{
The Relationship of Cloud Cover to Near-Surface Temperature and Humidity: Comparison of GCM Simulations with Empirical Data
}

\author{
Pavel Ya. Groisman, Raymond S. Bradley, and Bomin Sun \\ Department of Geosciences, University of Massachusetts, Amherst, Massachusetts
}

(Manuscript received 11 January 1999, in final form 28 June 1999)

\begin{abstract}
One of the possible ways to check the adequacy of the physical description of meteorological elements in global climate models (GCMs) is to compare the statistical structure of these elements reproduced by models with empirical data from the world climate observational system. The success in GCM development warranted a further step in this assessment. The description of the meteorological element in the model can be considered adequate if, with a proper reproduction of the mean and variability of this element (as shown by the observational system), the model properly reproduces the internal relationships between this element and other climatic variables (as observed during the past several decades). Therefore, to distinguish more reliable models, the authors suggest first analyzing these relationships, "the behavior of the climatic system," using observational data and then testing the GCMs' output against this behavior.

In this paper, the authors calculated a set of statistics from synoptic data of the past several decades and compared them with the outputs of seven GCMs participating in the Atmospheric Model Intercomparison Project (AMIP), focusing on cloud cover, one of the major trouble spots for which parameterizations are still not well established, and its interaction with other meteorological fields. Differences between long-term mean values of surface air temperature and atmospheric humidity for average and clear sky or for average and overcast conditions characterize the long-term noncausal associations between these two elements and total cloud cover. Not all the GCMs reproduce these associations properly. For example, there was a general agreement in reproducing mean daily cloud-temperature associations in the cold season among all models tested, but large discrepancies between empirical data and some models are found for summer conditions. A correct reproduction of the diurnal cycle of cloud-temperature associations in the warm season is still a major challenge for two of the GCMs that were tested.
\end{abstract}

\section{Introduction}

Many meteorological phenomena that change rapidly in time and space significantly affect the mean state of the climate system. Among these are cloud cover variations, which significantly (and immediately) alter the heat balance of the earth's climate system on an hourly time scale, but their effects are profound from seasonal through decadal timescales. Recent findings (Arking 1991; Henderson-Sellers 1992; Kaas and Frich 1995; Abakumova et al. 1996) show that variations of cloud cover have significantly contributed to contemporary climatic changes. It is known that, on average, the presence of clouds is associated with a cooler surface, but significant uncertainties are involved in assessing the role of cloudiness changes in the climate system under conditions related to increased greenhouse gases. Among these is the question: will cloud cover enhance

Corresponding author address: Dr. Pavel Groisman, UCAR Project Scientist, National Climatic Data Center, 151 Patton Avenue, Asheville, NC, 28801.

E-mail: pgroisma@ncdc.noaa.gov the process of climate changes (i.e., provide a positive feedback) or will it dampen any changes (i.e., provide a negative feedback)? Not all of these questions have answers today, and extensive international programs (e.g., GEWEX, ISLSCP, and ISCCP) ${ }^{1}$ targeting these answers are in progress. Two different approaches are generally used to address the feedback problems: modeling (Cess et al. 1991; Randall et al. 1994) and analysis of empirical data (Harrison et al. 1990; Gaffen and Elliott 1993; Groisman et al. 1994a,b, 1995, 1996, 1997). The efforts to match observational data, such as data from the Earth Radiation Budget Experiment (ERBE), with model output show large discrepancies among different modeling groups (Cess et al. 1992a,b, 1993; Potter et al. 1992; Wielicki et al. 1995). Modern GCMs parameterize effects of clouds differently and produce a wide range of apparent "effects" of cloudiness on

\footnotetext{
${ }^{1}$ Global Energy and Water Balance Experiment (GEWEX 1990), International Satellite Land Surface Climatology Project (Sellers et al. 1996), International Satellite Cloud Climatology Project (Rossow and Zhang 1995).
} 
climate (Cess et al. 1991; Potter et al. 1992; Randall et al. 1994; Yao and Del Genio 1999). One conclusion is certain from these model assessments, however: cloud cover is crucial for a proper assessment of the climatic system. Thus, uncertainty of cloud treatment in GCMs increases by a factor of 2 the range of uncertainty of future climate projections due to anthropogenic changes in greenhouse gases [Intergovernmental Panel on Climate Change (IPCC) 1996]. To diminish this uncertainty, a proper physical description of cloudiness and its relationships with other meteorological elements must be developed. To claim that this description is "proper," we have to be sure that a package of physical parameterizations in the model works on timescales from diurnal to decadal and fully describes the behavior of the contemporary climate system with variations in cloudiness. We propose using modern observations to check the reality of this package by testing the relationships between cloud cover ${ }^{2}$ and other meteorological elements.

\section{Methodology}

One of the possible ways to check the adequacy of the physical description of a meteorological element in the model is to compare the statistical structure of this element (mean, standard deviation, and spatial and temporal correlation) reproduced by models with the empirical data of the world climate observational system (Stouffer et al. 1994; Weare and Mokhov 1995; Del Genio et al. 1996; Polyak 1996; Goody et al. 1998). Groisman et al. (1995, 1996) suggested a further step in this assessment. The description of the meteorological element in the model is considered adequate if, with a proper reproduction of the mean and variability of this element (as shown by the observational system), the model properly reproduces the internal relationships between this element and other climatic variables. For example, a correct description of cloud cover should include an appropriate change in the temperature field when clouds are changing and vice versa. This is generally a more difficult task because instead of a proper fit of mean values of each of these fields, a proper fit of a set of physical processes that manifest themselves in interaction of these fields in the course of contemporary climate variations is required. Sometimes in the past, fits of the mean meteorological fields were achieved artificially by changing the physical parame-

\footnotetext{
${ }^{2}$ Cloud cover is only one of numerous characteristics of cloudiness However, sufficiently long time series with information about other cloudiness characteristics available from national archives are scant, and the definitions of these characteristics vary with time and by country. Therefore, we were not able to secure the hemispheric coverage for other cloudiness characteristics for our analyses, and we use only total cloud cover throughout this paper. Recent efforts by Hahn and Warren (1999) indicate that this data paucity may soon change.
}

ters of the GCMs from the solar constant to the depth of Hudson Bay. While due to such a "fitting" the corroboration with observations looks reasonable, the future use of these models for climate change studies became questionable. Beyond the present climate and paleoclimate reconstructions, each modeler group finds itself in uncharted waters and must rely upon accurate reproductions by their model of the physical processes rather than rely upon specific meteorological fields (Del Genio et al. 1996).

Groisman et al. (1996) suggested using the following statistics for a set of climatic variables $\phi$ to check the correct description of the interaction of element $y$ with these variables using empirical data:

$$
\mathrm{OE}(\phi \mid y \in D)=E(\phi)-E(\phi \mid y \in D),
$$

where $E()$ is a mathematical expectation and $E(\mid)$ is a conditional expectation. We consider these statistics as a diagnostic vehicle that allows the description of "overall effects" (OE) of the element $y$ on the climate, ${ }^{3}$ and thus we allow a check of the proper reproduction of these effects by GCMs. The term "OE" was introduced by Groisman et al. (1996) with a clear indication that despite the name, these statistics do not represent causal relationships or forcings but are bivariate associations between internal climate variables (e.g., cloud cover and temperature). Even the most vigorous proponent of cloud forcing ideas will have difficulty explaining how clouds "force" a decrease in atmospheric pressure and/ or an increase in wind speed near the surface. Yet changes in these variables are associated with the presence of clouds (Groisman et al. 1996), as are many other changes, including those in humidity and temperature fields. Our OE estimates are not causal relationships but characterize an average state of these associations as a result of numerous interactions within the climatic system. We continue to use the term "overall effect" throughout this paper but warn against its interpretation as a causal relationship.

To study the proper model description of the element " $u$ " when several other internal factors are involved and contribute to the process under consideration, the following statistic can be used: ${ }^{4}$

\footnotetext{
${ }^{3}$ For example, if $\phi$ is the top-of-the-atmosphere outgoing longwave radiation (OLR) flux, $y$ is cloudiness, and $D$ corresponds to clear-sky conditions, we obtain the "cloud forcing" of OLR as defined by Harrison et al. (1990) from the ERBE data.

${ }^{4}$ For example, if $\phi$ is humidity, $y$ is cloudiness, and $D$ corresponds to clear-sky conditions, $u$ is snow cover ( $a=$ snow-on-the-ground events, and $b=$ no-snow-on-the-ground events), and $x$ is ground surface temperature from a narrow range $(C)$, we get the effect of the presence of snow on the ground on humidity without contamination of this relationship by cloudiness and temperature variations (Groisman and Zhai 1995). When we want to exclude from consideration a contribution of a known factor, the POE statistics can be used as a supplementary tool.
} 


$$
\begin{aligned}
\operatorname{POE}(\phi|u| y \in D, x \in C) & \\
= & E(\phi \mid u=a, y \in D, x \in C) \\
& -E(\phi \mid u=b, y \in D, x \in C),
\end{aligned}
$$

where POE is the partial overall effect.

The class of Eqs. that (1) and (2) are in is wide and not restricted by examples presented in the footnotes and throughout this paper. By introducing OE statistics, we suggest constructing a series of nontraditional climatologies (e.g., climatology of clear skies; climatology of days with precipitation, with snow on the ground, and with calm conditions; and climatology of the weather along storm tracks) that differ distinctively from mean climate conditions. The present behavior of the climatic system will be more prominently seen in these situations that are far from the average climate conditions because (1) the tails of any distribution generally contain more information about that distribution than the values close to its average state and (2) the assessment of the "distinct" special conditions such as clear skies, calm weather, or the weather during precipitation events elucidates the relationships in the climatic system that prevail during these conditions and can be singled out and compared with similar relationships in the GCMs' output.

Mean monthly fields of the earth's climatic system remain quite stable, and their interannual variations constitute a small portion of weather variability in the timespace domain. It is possible to reconstruct these fields with a climate model that has incorrect parameters or dubious physics yet still do the reconstruction reasonably well. Regretfully, if after such a verification the model is applied to climatic change assessment, the results will be unreliable. It is much better if the interannual variability of these fields and synoptic scale variability are well described by the model. In such cases, we can state that the model is consistent with modern climate/weather variations and use it more confidently in experiments with changing external parameters (i.e., in climate change studies). ${ }^{5}$ To distinguish more reliable models that correctly incorporate climate variability, we suggest first analyzing this behavior using observational data for the past several decades and then testing the GCMs' output behavior against nature. Only those that pass this comparison are capable of delivering correct answers in experiments with external forcing, and this

\footnotetext{
${ }^{5}$ From this point of view, the Atmospheric Model Intercomparison Project (AMIP) (Gates 1992; Gates et al. 1999) is a large-scale test of the internal consistency of the atmospheric circulation and the land-surface interaction schemes of the participating GCMs. When comparisons are made between the GCMs and empirical data, variations of some meteorological fields (e.g., surface air temperature) are well reproduced by the AMIP runs (Gates et al. 1999) whereas other fields (cloudiness, soil moisture) are not (Weare and Mokhov 1995; Robock et al. 1998)
}

(we hope) will narrow the present uncertainty in climate change studies.

In this paper, we focus on one of the major trouble spots, cloudiness, and its interaction within the climatic system where parameterizations are still not well determined. We will consider overall cloud effect (OCE) on surface air temperature (OCET) and atmospheric humidity $(\mathrm{OCEH})$, defined either as temperature-humidity differences between average and clear sky weather conditions:

$$
\begin{aligned}
& \text { OCET } \\
& \quad=E(T)-E(T \mid \text { under clear sky conditions })
\end{aligned}
$$

and

$$
\begin{aligned}
& \text { OCEH } \\
& \quad=E(H)-E(H \mid \text { under clear sky conditions), }
\end{aligned}
$$

where $T$ is surface air temperature and $H$ is a characteristic of the near-surface atmospheric humidity (water vapor pressure, $e$, and/or specific humidity, $q$, were used throughout this paper), or (in the humid tropics) as temperature-humidity differences between average and overcast weather conditions (subscript "1"):

$$
\begin{aligned}
& \text { OCET }_{1} \\
& =E(T \mid \text { under overcast conditions })-E(T)
\end{aligned}
$$

and

$$
\begin{aligned}
& \mathrm{OCEH}_{1} \\
& \quad=E(H \mid \text { under overcast conditions })-E(H) .
\end{aligned}
$$

Here, we change the sign in (5) and (6) to make it comparable with (3) and (4).

We calculated Eqs. (3), (5), (4), and (6) without the concern that observational practice at night significantly interferes with our estimates. The problem that we keep in mind here is obvious difficulties with nighttime observations of cloudiness. To remedy this problem, Hahn et al. (1995) developed a moonlight criterion of cloudiness observations. The essence of their analyses is that they filter the nighttime cloud observations and use only those that were made under enough brightness (e.g., moonlight or twilight). This criterion significantly improved their nighttime cloudiness climatology, but if used, it significantly reduces the sample size of the nighttime observations. Our analyses indicate that this precaution is not crucial (Sun and Groisman 2000; Sun et al. 2000, hereinafter SGBK).

It is possible to normalize the $\mathrm{OCE}$ and $\mathrm{OCE}_{1}$ to take into account the "distance" between clear, overcast, and average sky conditions by dividing the differences in each meteorological element, $\phi$, by this distance. In this paper, we chose not to do this because not much new information is generated with this normalization during the intercomparison of our empirical estimates of mean daily OCE with those derived from GCMs. Sun et al. (1999; SGBK) further investigate the questions related 


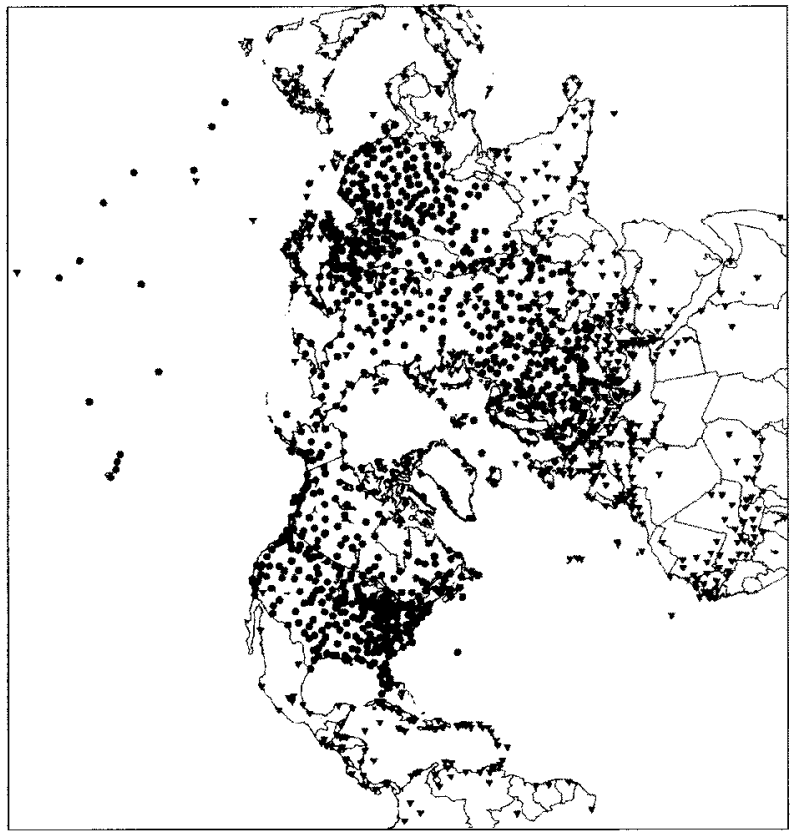

FIG. 1. Map of stations that were used in this analysis. Dots represent the stations with data delivered by the national meteorological services. Triangles show the stations with data taken from the Global Telecommunication System and/or supplementary networks that have less data than other stations in the region. The 36 stations in the Southern Hemisphere (Indonesia and a few tropical islands) are not shown in this map.

to normalization and describe the temporal OCET changes under contemporary climate conditions.

The appendixes describe several technical issues of the OCE estimation and the comparison of empirical OCE estimates with those derived from GCM output. It also provides information about the accuracy of our empirical OCET and OCEH estimates.

\section{Data and model output used}

In the comparison below, we used 1-h/3-h/6-h nearsurface meteorological data from more than 1500 meteorological stations distributed over the northern extratropical land (NEL) area and the tropics for the past several decades (Fig. 1). This dataset was described by Groisman et al. (1996), but then it was expanded with additional stations from southern and central Europe, Canada, the United States (especially from Florida, Hawaii, and the Pacific Islands), east Asia (China, Mongolia, and Japan), and the tropics (Africa, Central America, south and southeast Asia). The stations that are included in this dataset are reasonably well distributed over NEL, with a better than average coverage of the United States, Europe, eastern China, and the western part of the former USSR. This gives us an opportunity to calculate and map the statistics represented by Eqs. (3) and (4) over North American and north Eurasian land areas.
In tropical regions, we were able to retrieve most of the data with diurnal cycle resolution after 1972, but we consider them as preliminary (supplementary). These data (triangles in Fig. 1) were collected not from national meteorological data archives, as most of those for the NEL, but from the worldwide surface weather observations obtained from sources such as the Global Telecommunication System (GTS) and the Automated Weather Network (AWN) of the U.S. Air Force Central at Offutt Air Force Base, Nebraska. Although these data passed logical control and some other verification procedures (USAFETAC 1986), they still have numerous gaps and generally are considered less reliable than those delivered by the national meteorological services in offline mode. The above also means that practically all regionally specific comparisons shown below are made only for the NEL. This is a serious restriction for global assessment of cloud-cover parameterizations. Over the tropics and the oceans, we have not yet accumulated the necessary volume of synoptic information to perform our final analyses. We acknowledge that the associations of cloud cover and near-surface meteorological fields there can be different (Chanine 1995; Groisman et al. 1996; Sun and Groisman 1998; Sun et al. 1999; SGBK). Therefore, we consider our results for tropical land areas preliminary.

The output of the 10-yr-long AMIP runs with the GISS, MPI, UIUC, MGO, LMD, and CCC GCMs (period of 1979-88) and a 14-yr-long run from the NMC GCM (period of 1982-95) was used in this intercomparison. The models are those developed at the Goddard Institute for Space Studies (GISS); the Max Planck Institute, Germany (MPI); the University of Illinois at Urbana-Champaign (UIUC); the Main Geophysical Observatory, Russia (MGO); the Canadian Climate Centre (CCC); the Laboratoire de Météorologie Dynamique, France (LMD); and the U.S. National Meteorological Center (NMC). The Program for Climate Model Diagnosis and Intercomparison (PCMDI) publication by Phillips (1994) and references embedded in it are a good source because they summarize these AMIP GCM descriptions. There are some differences in time increments of the model outputs: GISS, UIUC, MGO, LMD, and NMC AMIP runs provide daily average data while the CCC output has a 6-h time increment and the MPI output has 12-h average values. This shows that for these GCMs (except the CCC AMIP run), we cannot assess the diurnal cycle effects of cloud cover on the near-surface meteorological fields and, thus, are restricting ourselves below to analyses of the mean daily effects. The UIUC modeling group performed a special rerun of their AMIP run and stored the 6-h time increments of the July model output. This was done especially in response to our request to assess further the details of the associations between cloudiness and nearsurface humidity fields in the UIUC model. 
(a)
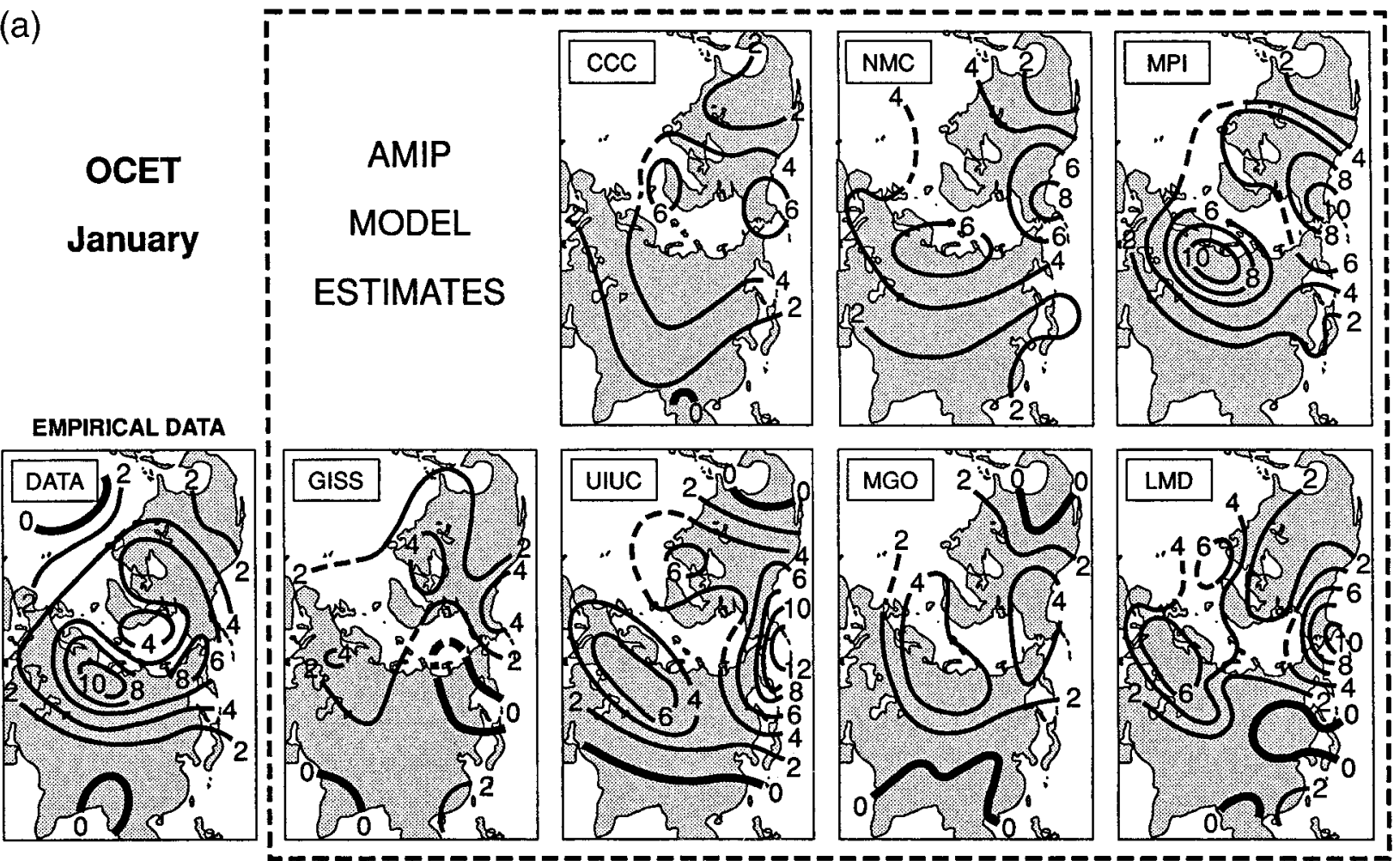

(b)

OCET

January


FIG. 2. Surface air temperature overall cloud effect, OCET $\left({ }^{\circ} \mathrm{C}\right)$, over only land areas as estimated from the AMIP runs of seven GCMs for temperature at $2 \mathrm{~m}$ above the ground (four right-hand columns of maps; the GISS AMIP model was run for temperature at $10 \mathrm{~m}$ above the ground) and from empirical data for temperature at the shelter level (1.5-2 m above the ground) for Jan, Apr, Jul, and Oct. 
(c)

EMPIRICAL DATA
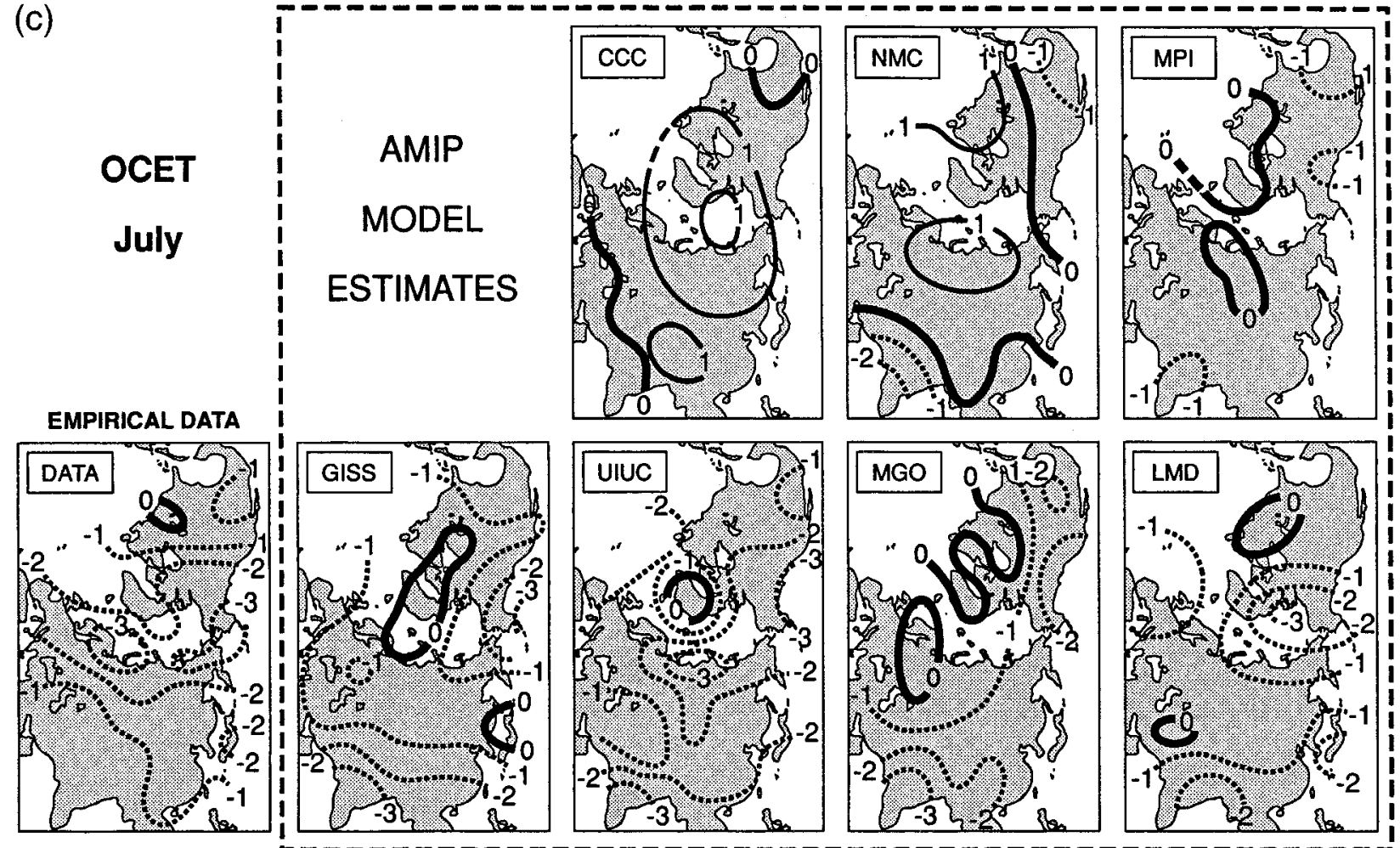

(d)

EMPIRICAL DATA
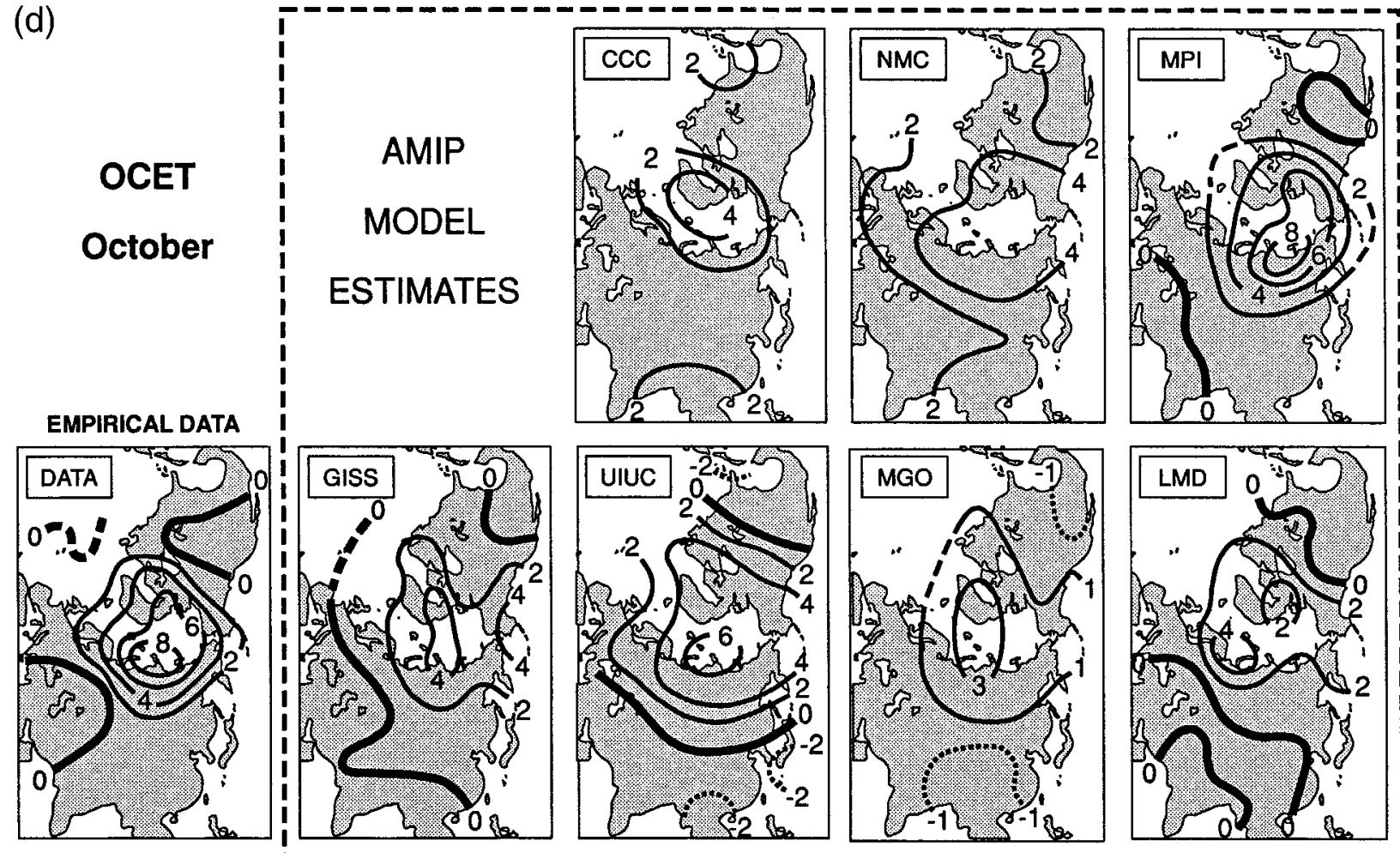

FIG. 2. (Continued) Clear-sky day is defined as a period when total cloudiness was less than 0.15. 


\section{Sensitivity of the surface temperature and humidity fields to the presence of clouds}

\section{a. Surface air temperature in the presence of clouds}

In Fig. 2, we compare the January, April, July, and October OEs of the presence of clouds on near-surface air temperature. In empirical data, OCET shows its obvious seasonality. In the Northern Hemisphere winter, OCET is positive, while in summer, the effect is opposite and cooling is associated with the presence of clouds. ${ }^{6}$ In the transitional seasons (April and October), in high latitudes, the surface temperature difference between average and clear sky conditions is positive, while over some midlatitudes and subtropical regions, the difference is negative. The magnitude of the overall effect of cloudiness on surface temperature has a circumpolar pattern. In general, the magnitude of surface temperature variation associated with cloud cover is larger in high latitudes than in low latitudes. Below, we compare, season by season, the OCET estimates between the observations and the GCMs over the NEL.

\section{1) JANUARY}

The mean daily OCET in January is warming; that is, clouds are associated with higher temperatures. The most prominent OCET is in high latitudes: a 4-8 K difference between average and clear sky conditions. All seven GCM AMIP runs tested reproduced the sign and the pattern of the winter OCET. Four GCMs (UIUC, MPI, CCC, and NMC) are able to correctly reproduce the magnitude of the OCET. The least accurate OCET reproductions are in the GISS and LMD AMIP runs. In these runs, the OCET in high latitudes varies in the range of $0-4 \mathrm{~K}$ and is underestimated by a factor of 2 or more. A negative OCET over east Siberia, which is seen in the GISS and LMD OCET estimates, is not supported by empirical data.

\section{2) APRIL}

The mean daily temperature difference in high latitudes in the empirical data still remains positive, while the magnitude is smaller than that in January. In certain midlatitudes and subtropical regions, the temperature difference turns out to be negative. The UIUC, MGO, LMD, and MPI models properly reproduce the above pattern, but the magnitude over the polar region in the UIUC and MPI models is higher than that in empirical data by $2-4 \mathrm{~K}$. In the MGO model, the cooling asso-

\footnotetext{
${ }^{6}$ Groisman et al. (1996) show that in the summer, the cloud effects over most of NEL have distinctive patterns and different signs in daytime and nighttime (cf. Fig. 3 in Groisman et al. 1996). Therefore, mean daily cloud effects in summer, which we are comparing now, are an algebraic sum of the strong patterns, which are quite different during the diurnal cycle.
}

ciated with cloud cover is disproportionately amplified over Asia. The CCC and NMC models basically reproduce the same pattern of temperature difference in high latitudes as in the observations, but they do not reproduce the cooling associated with cloudiness over some midlatitudes and subtropical regions. This peculiarity of the OCET pattern in these two GCMs becomes more visible in the summer season and will be discussed in detail in the next paragraph. In contrast, the high-latitude warming with cloud cover is not properly reproduced in the GISS model, where the OCET over the east Arctic region is negative.

\section{3) JULY}

The mean daily OCET in summer is cooling. The average climate is associated with a July temperature that is $1-2 \mathrm{~K}$ lower than clear sky conditions. As mentioned above, this is a manifestation of the daytime cloud effects (Groisman et al. 1996). Four AMIP runs (UIUC, GISS, LMD, and MGO) properly reproduce the sign, pattern, and magnitude of the July OCET. The MPI AMIP run reproduces the pattern and sign but shows some positive bias in OCET. In this run, the average climate is associated with temperatures $0-1 \mathrm{~K}$ lower than clear sky conditions.

The comparison of our empirical estimates of the OCET with two other AMIP runs (CCC and NMC) gave disturbing results. The sign of the July OCET in these two GCM AMIP runs is opposite to that observed. To clarify the consequences of these differences, let us assume a climate sensitivity experiment $\left(2 \times \mathrm{CO}_{2}\right.$, aerosol or solar forcing) or a paleoclimatic reconstruction that might use these models. In new (and unknown) climate conditions, the cloud cover can change in any direction, and many of the modern climate sensitivity experiments have shown a significant contribution of these changes to the results of such experiments (Intergovernmental Panel on Climate Change 1990, 1996). A wrong OCET sign then will produce an unpredictable bias in meteorological elements, surface air temperature, and cloudiness, thus affecting all changes in surface climatology associated with the forcing under investigation (or the paleoclimatic reconstruction). We are not able to foresee these unpredictable changes, but we can state that in the current climate (and the AMIP simulations forced by contemporary sea surface variations), the present versions of these two GCMs reveal strong contradictions with the observed climate. These contradictions should be fixed before these versions of the GCMs can be further used in any climate change assessments.

The mean daily OCET is an algebraic sum of hourly OCET, and these effects have opposite signs in day and night (Groisman et al. 1996). For the CCC and UIUC AMIP runs, we were able to expand our analyses of the summer OCET to assess day-night differences in the OCET. Figure 3 shows the afternoon and nighttime OCETs that were derived from these model AMIP runs 

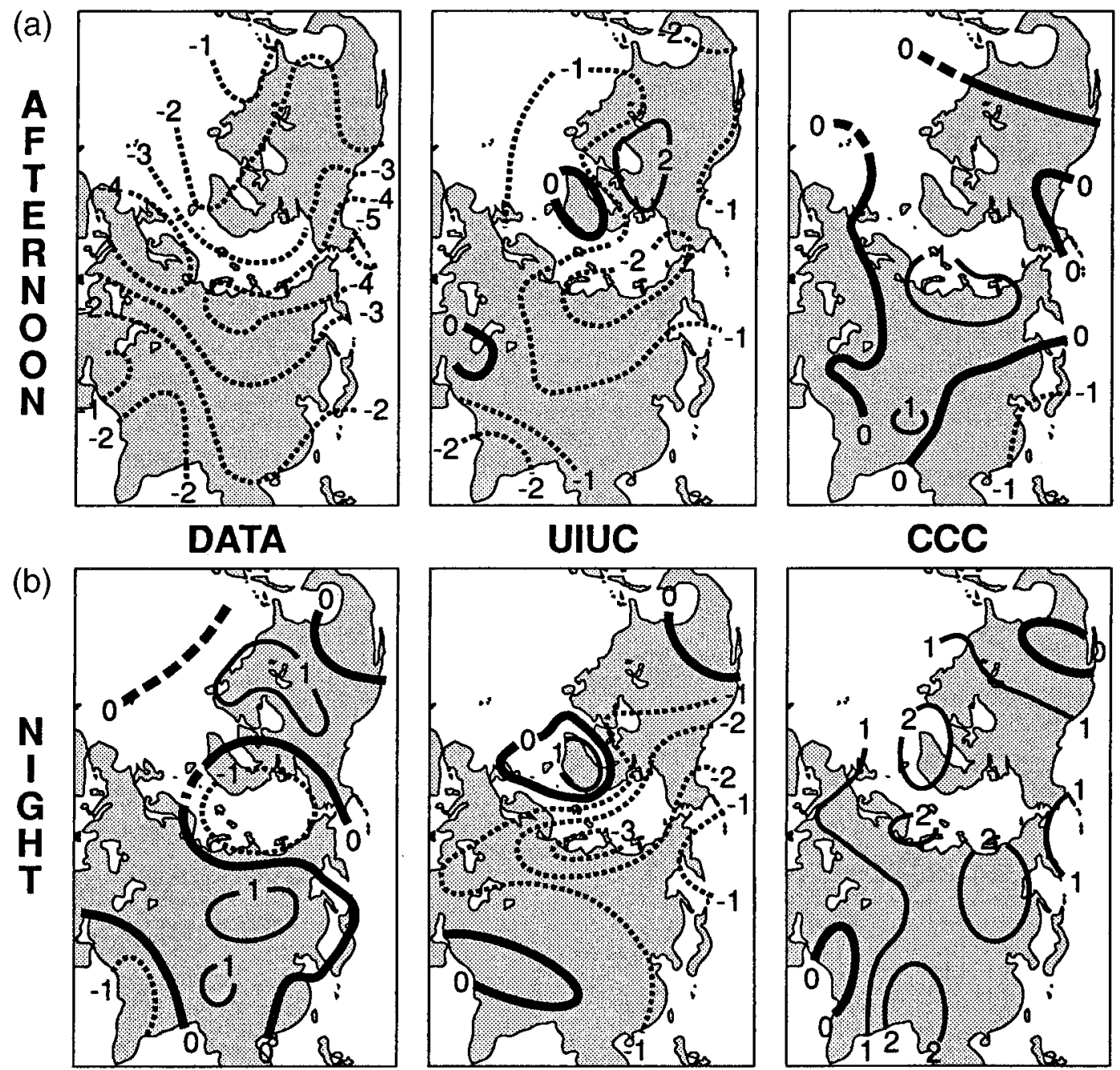

FIG. 3. Jul OCET $\left({ }^{\circ} \mathrm{C}\right)$ estimated over only land areas from the CCC and UIUC AMIP model runs and from empirical data: (a) local afternoon OCET and (b) nighttime OCET. Clear-sky and overcast days are defined as periods when total cloudiness was less than 0.15 and greater than 0.85 , correspondingly.

and empirical estimates. It is clear that the major problem revealed in Fig. 2 for summer OCET in the CCC model is in the daytime. Recent studies (Stuart and Isaac 1994; Isaac and Stuart 1996) specifically address the problems of the CCC model, especially the relationship between precipitation from cumulonimbus and towering cumulus and temperature in the Mackenzie River Valley. They explain the contradiction between observations and the model output as follows: "the model overpredicts the occurrence of convective clouds and underestimates the occurrence of stratiform clouds." Our analysis locates the season (summer), area (entire northern extratropical land area), and time of day (daytime) when the CCC model is out of range with observations. This strongly supports the hypothesis of Isaac and Stuart (1996) that something is wrong with the convective scheme of the CCC model under investigation.

The comparisons of July afternoon and nighttime
OCETs derived from the UIUC model with those derived from empirical data suggest that this model properly reproduces the afternoon cooling associated with cloudiness, although the magnitude of this cooling is 1-2 $\mathrm{K}$ lower than that in the empirical data. Unfortunately, the nighttime warming associated with clouds over the midlatitude regions is not shown in the AMIP run of the UIUC model. The mean daily OCET in the UIUC model is among the best in terms of its correspondence with the empirical data. But the amplitude of the OCET diurnal cycle in this model is much less than that in the observed OCET.

We were not able to assess in more detail the problems with the summer NMC OCET because we had only mean daily values from this AMIP run. However, a recent analysis by Higgins et al. (1996) indicates that the NMC GCM overestimates convective afternoon precipitation (at least over the Mississippi River Basin). This 
(a)

EMPIRICAL DATA

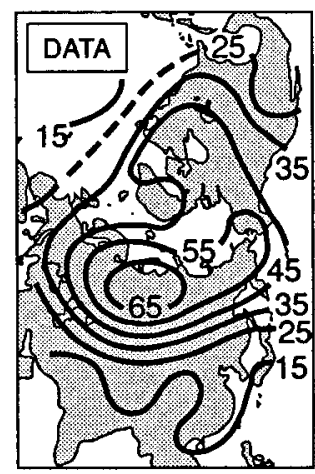

(b)
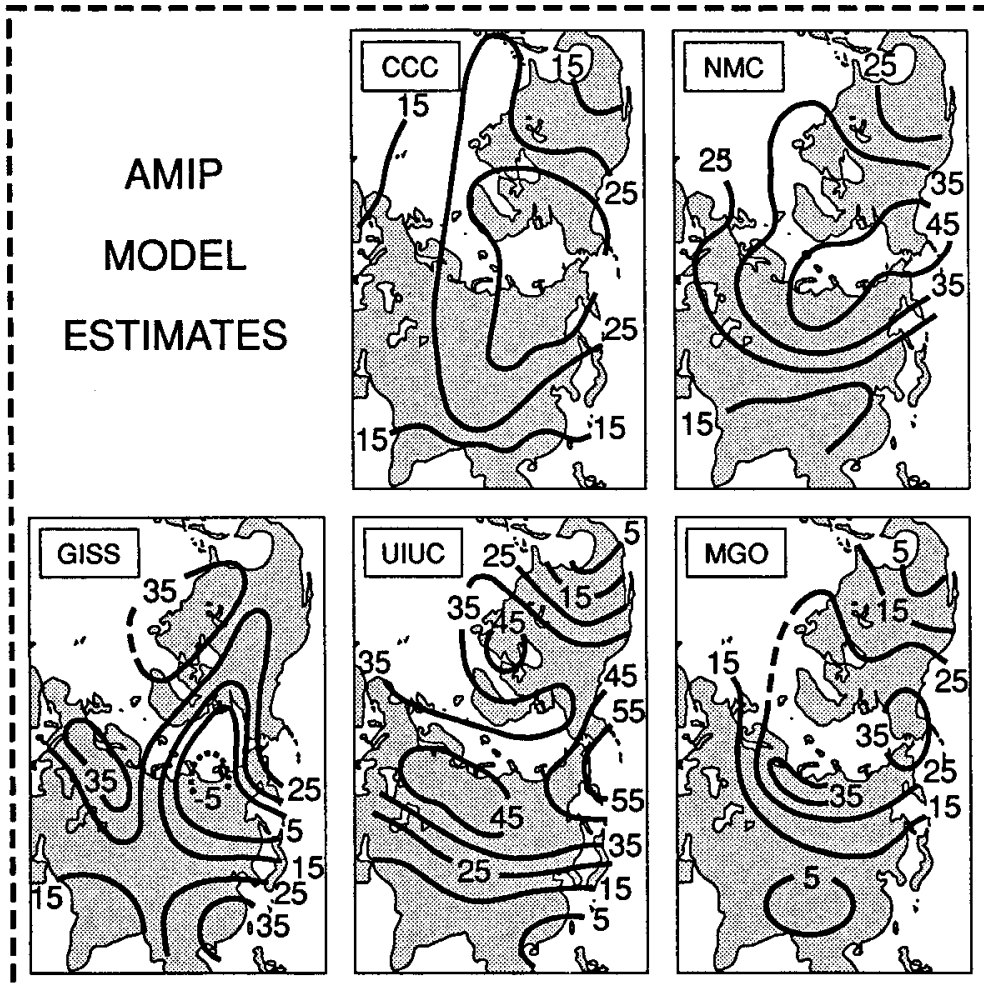
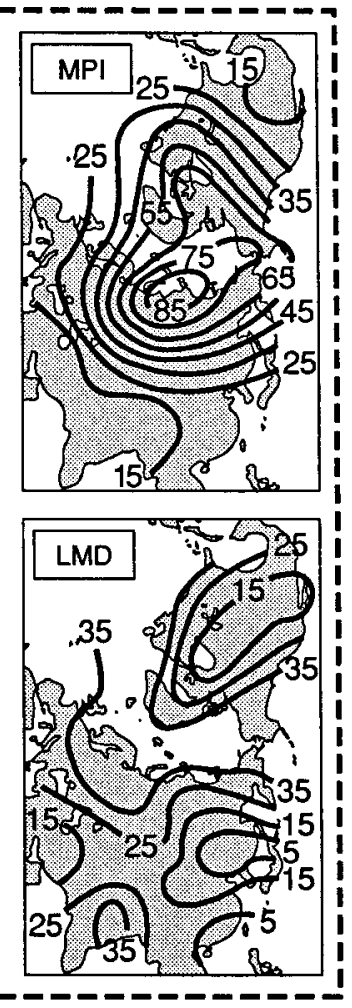

EMPIRICAL DATA

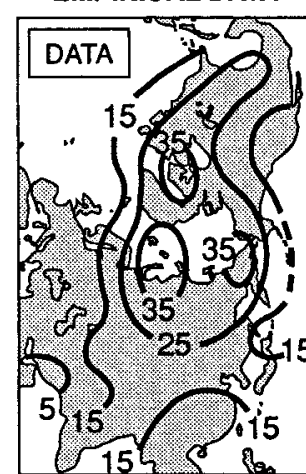

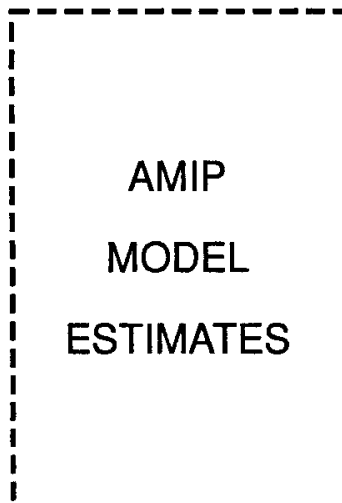

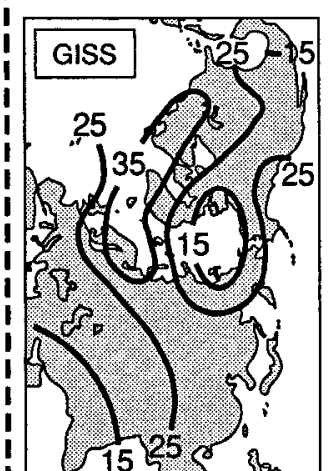

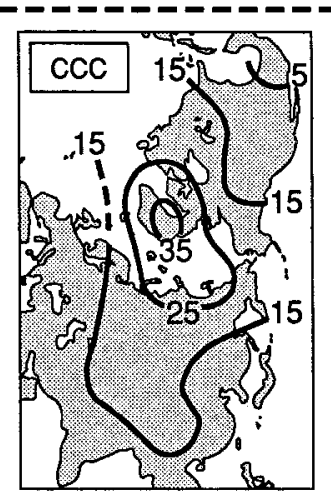
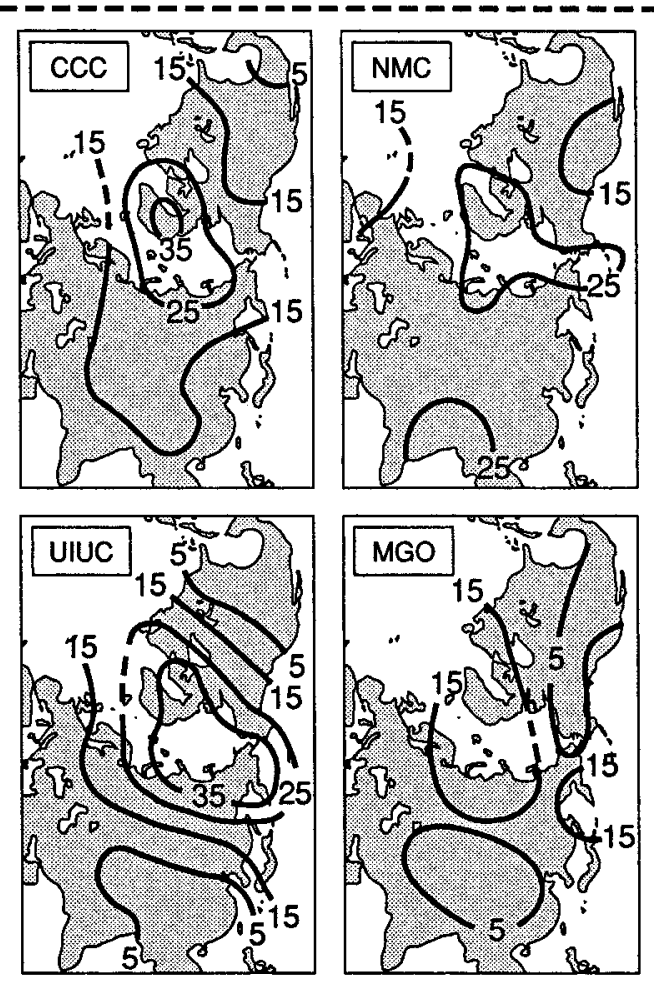

FIG. 4. The same as Fig. 2 but for the mean daily OCE on the near surface water vapor pressure (OCEH, in percent of the mean daily water vapor pressure $)$. The OCEH estimates are equal to $100 \%\left(P_{\text {avg }}-P_{\text {clear sky }}\right) / P_{\text {avg }}$ : Jan, Apr, Jul, and Oct. 
(c)

EMPIRICAL DATA
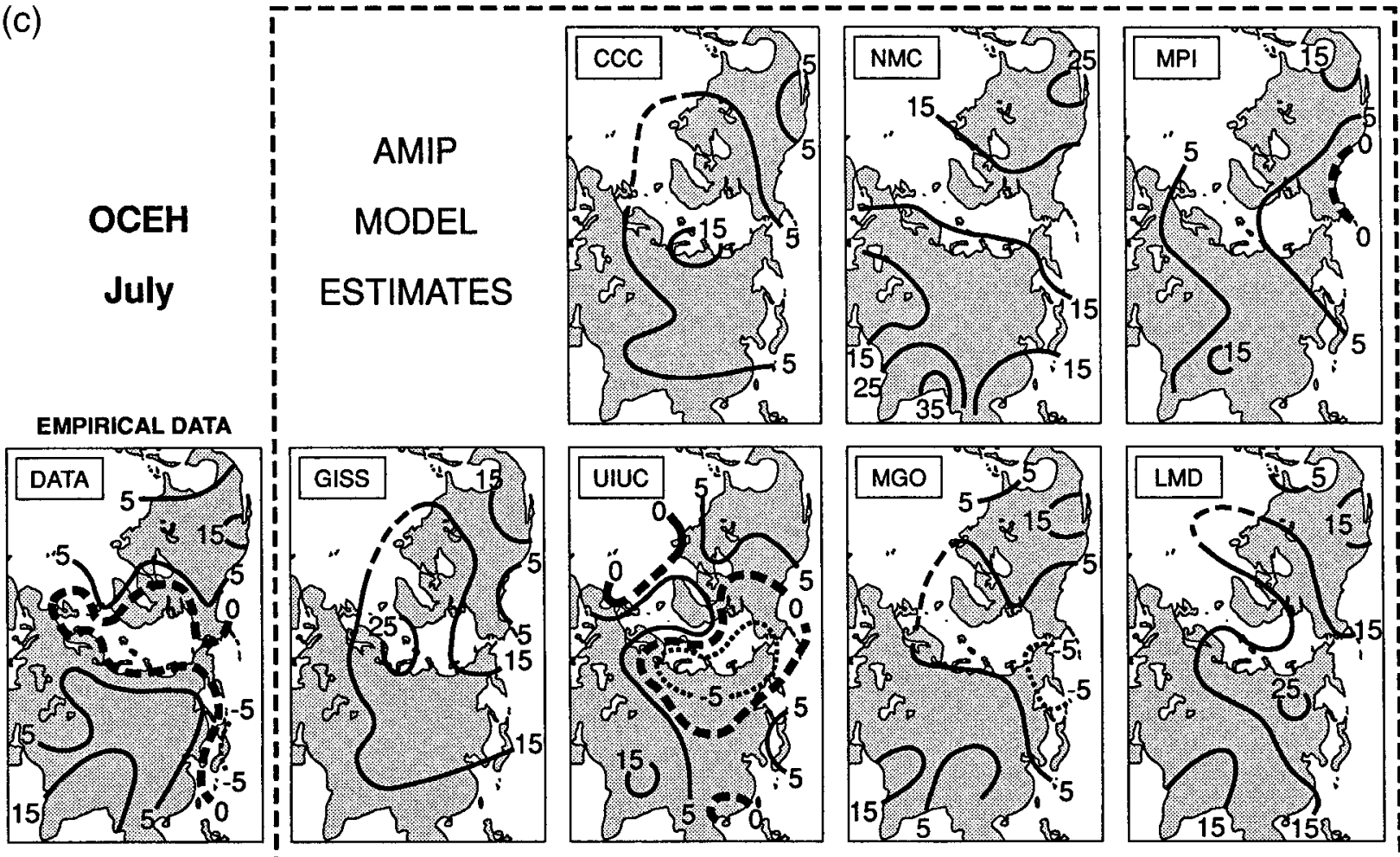

(d)
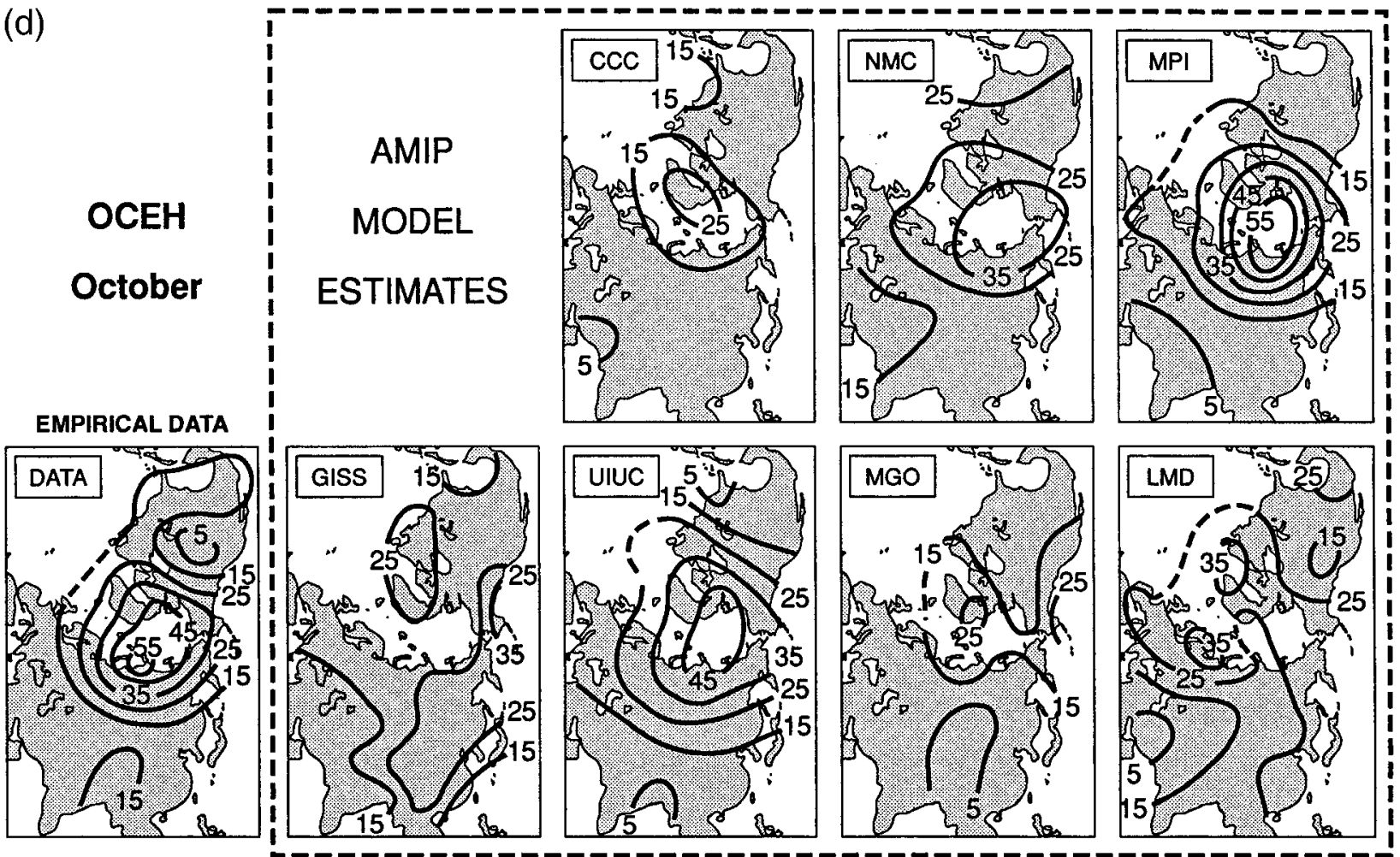

FIG. 4. (Continued) 
suggests that the model generates many more cumulus clouds than are necessary in conjunction with the warmer-than-necessary surface. These two factors may lead to "a warm surface-lots of clouds" association in the NMC AMIP runs output that contradicts empirical data.

\section{4) OCTOBER}

The UIUC and MPI models correctly reproduce the empirical OCET map, with the maximum warming over polar regions near $100^{\circ} \mathrm{E}$ and cooling over subtropical regions of North America and Eurasia. The GISS, NMC, and CCC models can basically produce the OCET pattern in empirical data, but the maximum warming center near $100^{\circ} \mathrm{E}$ in high latitudes doesn't appear on the maps derived from these models. In addition, the subtropical negative OCET is not reproduced in the CCC and NMC models. In the MGO and LMD models, the distribution of the surface air differences with cloud cover is similar to that in the observations except over east Asia, where these models produce negative OCET, which is opposite to the empirical data.

\section{5) CONCLUSION}

In conclusion, there is a general agreement in reproducing the associations between cloudiness and surface temperature in the cold season among all models tested. The largest intermodel difference in the OCET occurred in July. In comparison with the other six AMIP runs, the UIUC run is the most effective in producing the mean daily OCET. We were able to compare the diurnal cycle of the OCET with empirical data for only two GCMs-CCC and UIUC. One of these models, UIUC, performs much better than the other GCM and shows a proper sign and pattern of the mean daily OCET and, what is especially important, the afternoon OCET. However, the UIUC model does not produce the midlatitude nighttime warming associated with cloud cover. Thus, we can conclude that for modern climate modeling, a proper reproduction of the OCET for the diurnal variation of the surface air temperature is still a major challenge.

\section{b. Near-surface humidity fields in the presence of clouds}

There is a difference in characteristics that were selected by different model groups to represent the nearsurface humidity field in their AMIP runs. Four GCMs (GISS, NMC, LMD, and CCC) provide information about specific humidity, the UIUC model output provides absolute humidity, the MGO model output provides water vapor pressure, and the MPI model output contains dewpoint temperatures at the shelter level. ${ }^{7}$ The

\footnotetext{
${ }^{7}$ For the GISS AMIP run, we have specific humidity data at the first model level, that is, approximately $200 \mathrm{~m}$ above the ground.
}

humidity characteristic that we selected for our intercomparison from empirical data is water vapor pressure. In Fig. 4, we present its mean daily changes in the presence of cloud cover in percent of average water vapor pressure. ${ }^{8}$ For the purpose of comparability, we use the percentage of the variation of water vapor pressure between average and clear-sky conditions to present our OCEH estimates. Therefore, when the average water vapor pressure in the GCM deviates from its observed values, these deviations also contribute to the $\mathrm{OCEH}$ estimates shown in Fig. 4.

Empirical data show that the OCEH is positive in all four seasons (except for the Arctic and wet and cloudy North Pacific coastal areas), indicating that clear-sky conditions are usually associated with less-than-average atmospheric water vapor. In winter, the overall magnitude of this relative change in the Northern Hemisphere is larger than in summer. Below we compare, season by season, the OCEH estimates between the observations and the GCMs over the NEL.

\section{1) JANUARY}

In the empirical observations, the relative change of water vapor pressure increases with latitude, reaching $45 \%$ or more over the northeastern tip of North America, the Arctic region, and central Siberia. This phenomenon is related to the decrease of water vapor content in the atmosphere from low to high latitudes. The UIUC, MPI, NMC, CCC, LMD, and MGO models basically reproduce this water vapor change pattern. But there is a positive bias $(15 \%-30 \%)$ in the MPI model in high latitudes and a negative bias (10\%) in the CCC model. Over the entire Northern Hemisphere, the MGO and LMD models reproduce the OCE with a $10 \%$ negative bias, as compared to the empirical data. The GISS model cannot properly reproduce the observed water vapor change distribution. There even exists a negative difference of water vapor pressure between average and clear-sky conditions over the polar region near $140^{\circ} \mathrm{E}$ in the OCEH, which was reproduced by this model.

\section{2) APRIL}

In April, the OCEH magnitude (in percent) is smaller than in January, but the whole OCEH pattern in NEL

\footnotetext{
${ }^{8}$ For the CCC AMIP run, we evaluate the OCEH for each hour and then construct its daily average value. For other GCMs and for empirical data, we used method two of the calculations (see appendix A). For the MPI AMIP run, the 12-h mean values of dewpoint temperature were converted to water vapor pressure values using the Magnus formula beforehand. We checked the effect of such a conversion (when applied to empirical data) and found its contribution to our estimates to be negligible. This indicates that it does not matter which humidity characteristic was used for the estimates shown in Fig. 4. Therefore, a higher sensitivity of the near-surface humidity field to cloud cover that was revealed for the MPI AMIP output is not a product of a different mean 12-h averaged characteristic of humidity in the model output.
} 
is similar in these two months. The OCEH patterns derived from the UIUC, MPI, CCC, NMC, and MGO models are roughly in line with the observed patterns. Still, the MPI model overestimates the OCEH magnitude in high latitudes, the NMC and CCC models underestimate the OCEH value by about $10 \%$ in midlatitudes, and there is a $10 \%$ negative bias in the OCEH derived from the MGO model over land areas of the Northern Hemisphere. In the GISS model over the Arctic, the differences in water vapor pressure are the smallest, which is opposite of that in the empirical data.

\section{3) JULY}

The summer pattern of the OCEH is totally different from other seasons. The maximum water vapor pressure difference under average and clear-sky conditions occurs over the Tibetan Plateau and the Rocky Mountain region of North America instead of the polar regions (as in winter, spring, and autumn). Although the absolute values of the summer OCEH are the greatest, their magnitude in percent is the smallest and the value of the maximum-value contour line is only $15 \%$. There are larger differences in reproducing the empirical OCEH among the models under consideration. The UIUC, NMC, and MGO models are the only ones that can reproduce the whole pattern in the empirical observations, including the maximum water vapor pressure centers, but the magnitude of the OCEH reproduced by the UIUC model over these regions is $5 \%$ less than observed. There are significant biases over polar regions in the estimates derived from the GISS and NMC models. In both these models, over most of the polar regions, the water vapor pressure difference (in percent) is larger than in the observations, especially in the GISS model, where the difference compared with observations can reach about $20 \%$. In the CCC model, the pattern of the OCE on surface humidity is almost opposite to that in the empirical data, and in this model, the strongest OCEH still remains over high latitudes. Noticeably, in all seven models, there is the same maximum in the OCEH over the Tibetan Plateau and Rocky Mountains as in the observations.

For this midsummer month, we also analyzed the overall effect of cloudiness on diurnal variations of surface humidity in empirical data and in the CCC and UIUC models (not shown). In general, the OCEH pattern estimated from the observations in afternoons is similar to that at nighttime. Both patterns are similar to the above-mentioned mean daily pattern. The difference in the OCEH between afternoon and nighttime is that the magnitude of the afternoon OCEH is larger than at nighttime by about $5 \%-10 \%$. The diurnal variation of the OCEH in the UIUC model is the same as that in the empirical data, but in the CCC model, the diurnal variation of the OCEH observed in the empirical data is not reproduced.

\section{4) OCTOBER}

The pattern of the OCEH in empirical observations is similar to that in April. The UIUC, MPI, NMC, CCC, and MGO models fundamentally reproduce this pattern, but the MPI model overestimates the value over polar regions by about $10 \%$ and the $\mathrm{MGO}$ and $\mathrm{CCC}$ models underestimate the value by about $10 \%$ over most areas of the Northern Hemisphere. The GISS model cannot correctly reproduce the pattern of the autumn OCEH.

\section{5) Conclusion}

Many studies have verified that water vapor in the atmosphere has a positive greenhouse effect. That is, much more water vapor content can cause an increase in surface temperature, and vice versa. However, the relationship between the variations of surface water vapor pressure and surface air temperature associated with cloudiness seems complicated. In winter, an increase in surface water vapor is associated with cloud cover (Fig. 4) and corresponds to a warmer surface (Fig. 2). However, in summer, the same figures show that an increase in water vapor pressure associated with cloud cover is related to cooling at the surface. This situation also exists in the diurnal variation of water vapor pressure. The physical processes involving cloudiness-water vaporsurface temperature interaction need further investigation. These processes are most visible in the Tropics, and therefore the assessment of tropical OCET and $\mathrm{OCEH}$ is singled out in the next section.

\section{Surface air temperature and humidity in the Tropics in the presence of clouds}

The accumulation of synoptic data from the Tropics gives us an opportunity to make a pilot analysis of the effects of the presence of clouds in the tropical atmosphere on the near-surface meteorological fields. The standard approach that we applied to the extratropical atmosphere in the previous sections does not work well in the Tropics because we were not able to accumulate the necessary amount of clear-sky meteorological events in the daytime anywhere in the humid Tropics. We still use the clear-sky observations to characterize the nighttime effects of clouds, but only as an additional tool to check our results for nighttime cloud effects. For the daytime, we have to use a different statistic to describe cloud effect, and so we selected $\mathrm{OCE}_{1}$ (the difference between the values of the meteorological element, $\phi$, under average and overcast climate conditions). We used $\mathrm{OCE}_{1}$ throughout this section for both daytime and nighttime, and we verified our results/conclusions for the nighttime cloud effects using OCE. This allowed us to proceed with an assessment of the mean daily $\mathrm{OCE}_{1}$ from all seven GCMs in the wet Tropics. In the tropical regions, cloud diurnal variations dominate in the wide range of timescales exhibited by clouds and influence 
TABLE 1. Specific humidity, $q\left(\mathrm{~g} \mathrm{~kg}^{-1}\right)$, and overall cloud effect on surface air temperature, $\mathrm{OCET}_{1}(\mathrm{~K})$, in tropical regions.

\begin{tabular}{|c|c|c|c|c|c|c|c|c|c|}
\hline & \multirow[b]{2}{*}{ Stations } & \multicolumn{2}{|c|}{ Jan } & \multicolumn{2}{|c|}{ Apr } & \multicolumn{2}{|c|}{ Jul } & \multicolumn{2}{|c|}{ Oct } \\
\hline & & $q$ & $\mathrm{OCET}_{1}$ & $q$ & $\mathrm{OCET}_{1}$ & $q$ & $\mathrm{OCET}_{1}$ & $q$ & $\mathrm{OCET}_{1}$ \\
\hline \multicolumn{10}{|l|}{ Afternoon } \\
\hline Central and western Pacific & 9 & 17 & -0.5 & 18 & -0.6 & 19 & -0.6 & 19 & -0.6 \\
\hline Southeast Asia (north of the equator) & 44 & 13 & -1.4 & 17 & -1.5 & 19 & -1.0 & 17 & -1.4 \\
\hline South Asia & 23 & 13 & -1.4 & 17 & -1.5 & 19 & -1.0 & 17 & -1.4 \\
\hline Central and South America & 72 & 15 & -1.1 & 16 & -0.9 & 17 & -0.8 & 17 & -1.0 \\
\hline Africa, Sahel & 49 & 5 & -1.3 & 8 & -0.9 & 16 & -1.4 & 12 & -1.5 \\
\hline The Hawaiian Islands & 4 & 13 & -1.3 & 13 & -0.9 & 14 & -0.7 & 15 & -0.9 \\
\hline Mountains & 10 & 8 & -2.2 & 9 & -1.3 & 13 & -1.0 & 9 & -1.5 \\
\hline \multicolumn{10}{|l|}{ Nighttime } \\
\hline Central and western Pacific & & 17 & -0.1 & 17 & -0.1 & 18 & -0.1 & 18 & -0.1 \\
\hline Southeast Asia (north of the equator) & & 11 & 0.3 & 15 & -0.4 & 19 & -0.3 & 16 & -0.1 \\
\hline South Asia & & 14 & 0.6 & 16 & -0.4 & 18 & -0.3 & 16 & 0.4 \\
\hline Central and South America & & 14 & 0.2 & 15 & 0.2 & 17 & -0.1 & 16 & -0.0 \\
\hline Africa, Sahel & & 5 & 0.6 & 9 & 0.5 & 16 & -0.5 & 14 & 0.2 \\
\hline The Hawaiian Islands & & 12 & 0.9 & 12 & 0.3 & 14 & 0.1 & 14 & 0.3 \\
\hline Mountains & & 8 & 0.9 & 10 & 0.3 & 13 & 0.1 & & N/A \\
\hline
\end{tabular}

the diurnal cycle of surface heat balance (Hartmann et al. 1991). We were able to separate (and assess) the day-night differences in the model $\mathrm{OCE}_{1}$ for only the CCC and UIUC GCMs.

The $\mathrm{OCET}_{1}$ and $\mathrm{OCEH}_{1}$ in the wet Tropics do not have a distinctive pattern, and thus, instead of mapping them, we accumulated in Table 1 our area-averaged $\mathrm{OCET}_{1}$ estimates based on empirical data over several regions shown in Fig. 5. The regions have been selected using geographical and climatological considerations and were sorted by the type of seasonal cycle of nearsurface atmospheric humidity into three large groups: the all-year around "wet" region, the monsoon regions with a strong seasonal cycle of atmospheric humidity, and the dry (semiarid) region of the Hawaiian archipelago. Separate from the regions shown in Fig. 5, we singled out an additional group of stations (10 stations) located on the mountainous plateaus in Africa, Asia, and Central America where dry conditions prevail all year.

\section{a. OCE in low latitudes (empirical estimates)}

We found negative $\mathrm{OCET}_{1}$ in daytime over all tropical regions in each season. At nighttime, the sign of OCET varies with season and geographic location. In the tropical dry zones (e.g., the Hawaiian Islands and mountainous plateaus), a pronounced diurnal $\mathrm{OCET}_{1}$ cycle exists in each season. Over the tropical monsoon areas, the sign of the nighttime OCET 1 changes with season. Over the humid Tropics (central and western Pacific), negative nighttime $\mathrm{OCET}_{1}$ is observed throughout the year. Apparently, the diurnal OCET $_{1}$ variations in the Tropics north of the equator are different from those in the NEL. In January, over most of the NEL, surface warming is associated with the presence of cloudiness in both daytime and nighttime, and in July, OCET is negative in daytime and positive in nighttime. Therefore, in the Tropics in January, the daytime OCET ${ }_{1}$ is the opposite of that in the NEL, and during nighttime, it is the same as in the NEL. In July, during the daytime, the

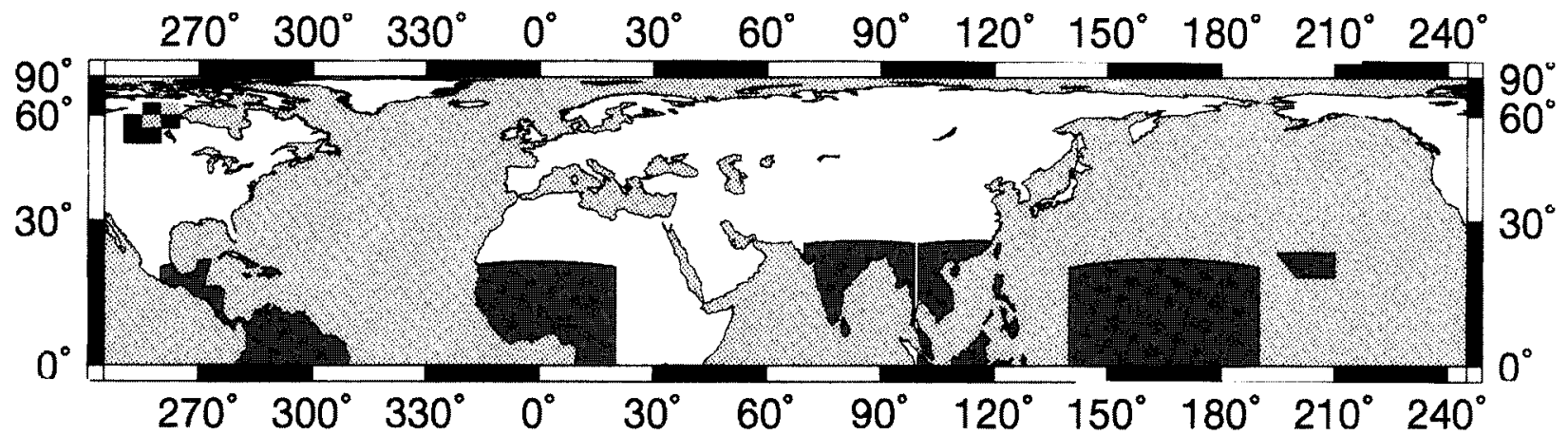

FIG. 5. Regions where the overall cloud effects on tropical temperature and humidity have been assessed. The OCE ${ }_{1}$ estimates were averaged over the stations embedded in these regions and are presented in Table 1. Mountainous stations (not shown) are spread over three continents in this map. 
negative sign of $\mathrm{OCET}_{1}$ is maintained throughout all latitudes, while during the nighttime in the Tropics, different regions have different OCET $_{1}$ signs.

$\mathrm{OCEH}_{1}$ (not shown) does not vary dramatically over the Tropics in the diurnal cycle. The water vapor pressure in the Tropics is much larger than that in the extratropical regions; therefore, the percentage of water vapor pressure variations associated with cloudiness are smaller than in the midlatitudes or high latitudes (varying by absolute value from 5\%-15\%). Among the new features that were not observed in the NEL, we encountered negative $\mathrm{OCEH}_{1}$ in both April and July over southeast Asia. In short, the association of cloudiness with surface humidity generally is the same between extratropical and tropical regions.

\section{b. OCE in Tropics in the GCM AMIP runs}

At present, of the seven AMIP GCM runs, only the UIUC and CCC models provide us with 6-hourly outputs, and the output from the UIUC model is only for July. The specifics of the OCE in tropical regions are mostly in the diurnal cycle in the warm/wet season. Therefore, in this section, we focus on comparisons between daytime and nighttime empirical $\mathrm{OCET}_{1}$ and $\mathrm{OCEH}_{1}$ estimates and those derived from the UIUC and CCC GCMs during the midsummer month of the Northern Hemisphere-July. Because the model grid resolution cannot cover small islands, four continental regions shown in Fig. 5, southeast Asia, south Asia, west Africa, and Central and South America, are selected for comparison with the observations.

In the UIUC model, the diurnal cycle of the OCET is simulated quite well, reproducing the negative $\mathrm{OCET}_{1}$ over these four monsoon regions in both daytime and nighttime. The simulated $\mathrm{OCEH}_{1}$ in the UIUC model is not in full agreement with the observations. At nighttime, it is positive over all four regions, but in the empirical data, this happens only over south Asia and tropical regions of America. In daytime, in the UIUC model, the $\mathrm{OCEH}_{1}$ over Central and South America is negative, which contradicts the empirical $\mathrm{OCEH}_{1}$ estimates. Over three other monsoon regions, the signs of empirical and UIUC daytime $\mathrm{OCEH}_{1}$ coincide.

In the CCC model, the daytime $\mathrm{OCET}_{1}$ in the tropics is in agreement, while the nighttime $\mathrm{OCET}_{1}$ is almost opposite to the observations. In that model, only over south Asia is there a slightly negative temperature difference between overcast and average situations, which is in line with empirical estimates (also see Fig. 3). The simulated $\mathrm{OCEH}_{1}$ in the $\mathrm{CCC}$ model is basically in agreement with observations, except that the magnitude of the $\mathrm{OCEH}_{1}$ in the CCC model is smaller than that in the empirical estimates.

\section{Water vapor and the nighttime OCET}

In this section, the OCET specifically refers to the nighttime. Over the NEL, the nighttime OCET remains
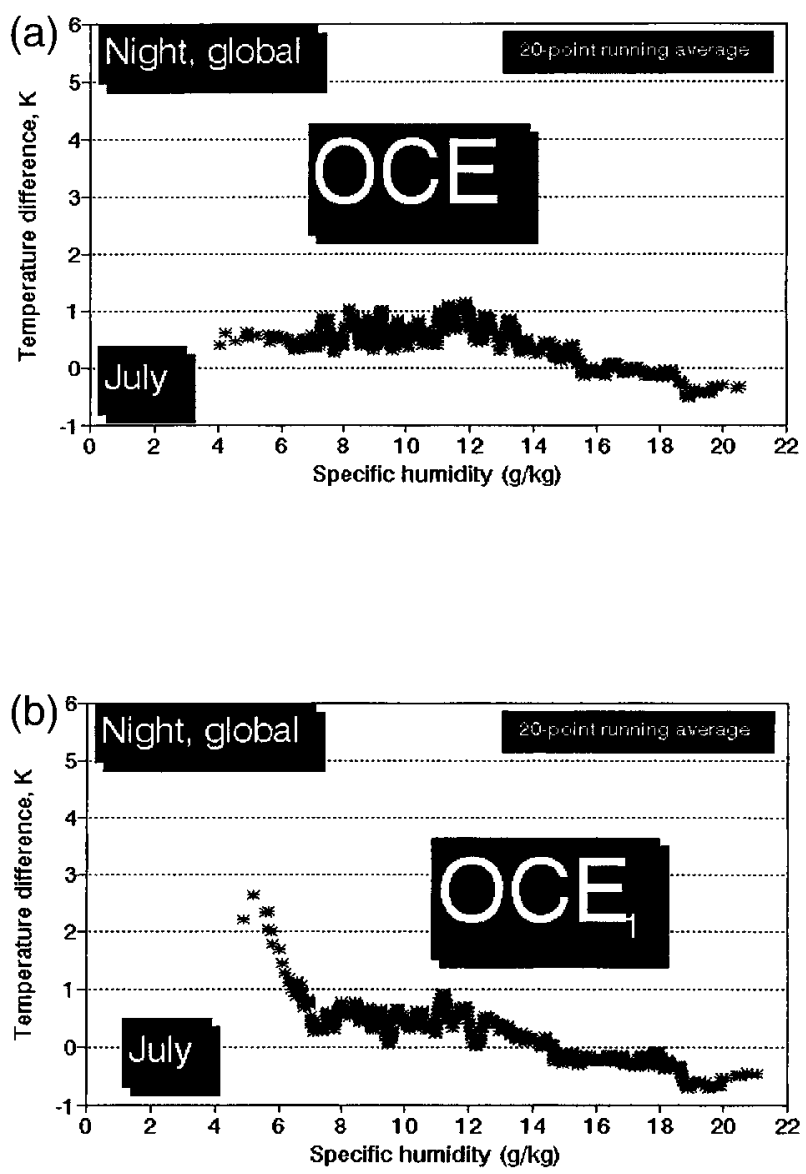

FIG. 6. Nighttime overall cloud effect on the July surface air temperature (OCET and OCET $_{1}$ ) in the Northern Hemisphere south of $60^{\circ} \mathrm{N}\left({ }^{\circ} \mathrm{C}\right)$ vs surface air specific humidity $q\left(\mathrm{~g} \mathrm{~kg}^{-1}\right)$. Empirical estimates at each location (totally approximately 1000 sites) have been sorted by $q$ and smoothed by a 20-point running average procedure.

positive and declines with the decrease of geographic latitude and with the change from winter to summer (in summer in polar regions, the nighttime OCET is negative due to the polar day phenomenon). Over the Tropics in winter, the nighttime OCET is positive over all tropical regions except the western and central Pacific, but in summer over monsoon regions and in the permanent convection zone of the central and western $\mathrm{Pa}-$ cific, the OCET becomes negative, while over dry tropical regions it remains positive.

Sun and Groisman (1998) examined the association between near-surface humidity and the nighttime OCET south of $60^{\circ} \mathrm{N}$ in each season. These results (only for summer season) are shown in Fig. 6 for the empirical estimates of nighttime OCET and in Fig. 7 for the estimates derived from the UIUC and CCC AMIP runs. In those figures, the abscissa represents the surface specific humidity $q\left(\mathrm{~g} \mathrm{~kg}^{-1}\right)$ and the ordinate shows the OCET/OCET $_{1}$ estimates (K). We also constructed global maps of surface-specific humidity in order to locate the 

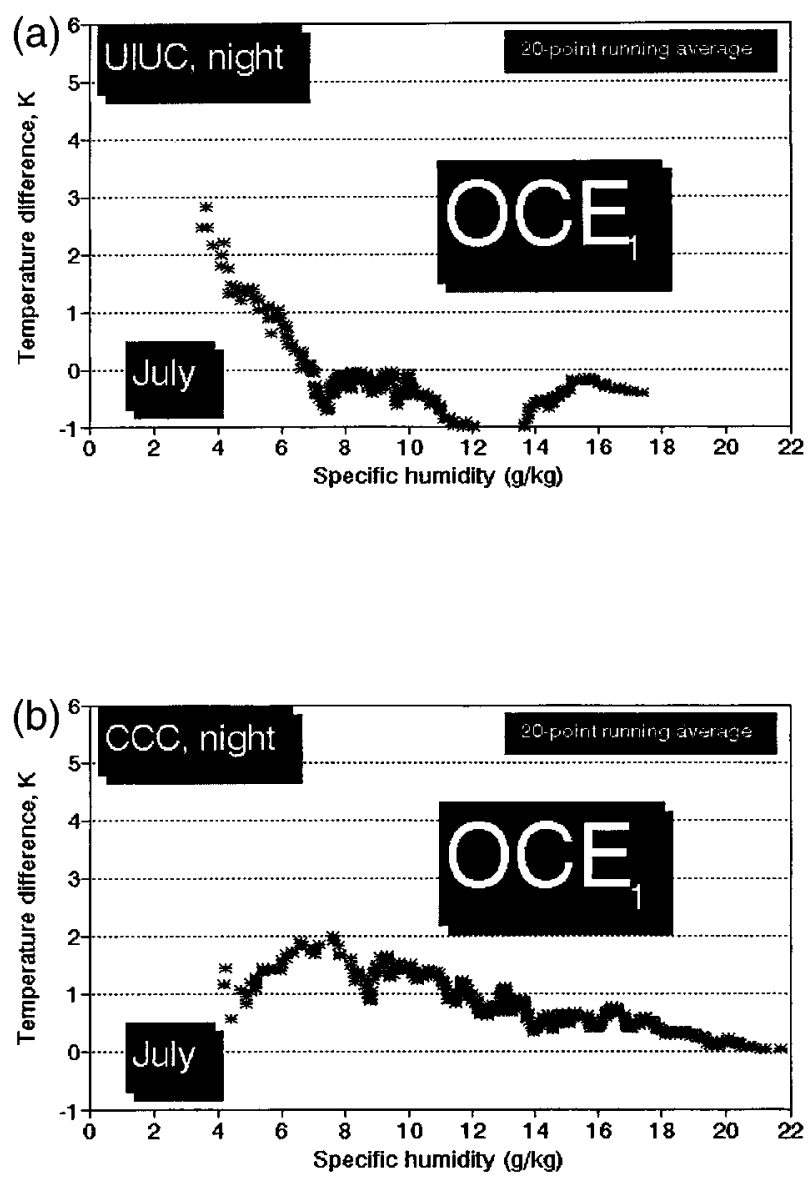

FIG. 7. Nighttime overall cloud effect on the Jul surface air temperature $\left(\mathrm{OCET}_{1}\right)$ in the Northern Hemisphere south of $60^{\circ} \mathrm{N}\left({ }^{\circ} \mathrm{C}\right)$ versus surface air specific humidity $q\left(\mathrm{~g} \mathrm{~kg}^{-1}\right)$. Estimates are based on the AMIP runs with UIUC and CCC global climate models (landonly grid cells are used to make it comparable with Fig. 6).

geographic position of the point on the functional curve between the OCET and surface water vapor. We found that in each season, the OCET significantly depends on $q$, and the relationship between them is nearly linear.

Figure 6 shows the empirical OCET and OCET $_{1}$ estimates for July at night. Hourly data of approximately 1000 stations qualified for use in constructing this figure. Initially, we calculated the point OCET and OCET estimates. They were considered valid point estimates when we were able to find at least 30 clear-sky (overcast) cases in the station's record. Then, these point estimates were sorted by specific humidity and smoothed by a 20 point running average process. This figure shows an important (and previously unreported) property of the night tropical atmosphere that can affect our understanding of the self-regulatory mechanisms of climate variations and, specifically, the bounds for projected greenhouse warming. Regression analysis of the unsmoothed data shown in Fig. 6 gives

$$
\begin{array}{rlrl}
\text { OCET } & =1.25-0.07 q & & \left(R^{2}=0.09\right) \quad \text { and } \\
\text { OCET }_{1}=1.4-0.10 q & & \left(R^{2}=0.26\right) .
\end{array}
$$

The regressions above show that the nighttime OCET is closely correlated to the surface water vapor, which, in a significant way, determines its geographical and seasonal variations. With the increase of surface water vapor, the nighttime warming associated with clouds is linearly reduced and even reversed to cooling when the surface-specific humidity surpasses a certain value (about $15.5 \mathrm{~g} \mathrm{~kg}^{-1}$ ).

Satellite measurements show that warmer tropical oceans as a whole are associated with a reduced longwave warming cloud effect (Zhang et al. 1996). This conclusion is the same as ours, although Zhang et al. (1996) used sea surface temperature instead of humidity to assess the relationship of cloud cover and the radiative budget at the top of the atmosphere in the Tropics. ${ }^{9}$ In low latitudes, the atmosphere contains much more water vapor, which absorbs some longwave radiation that is directed from the surface and from cloud cover. Thus, the exchange between clouds and the surface becomes weaker and affects OCET. Stephens et al. (1994) showed how the difference between clear and cloudy sky longwave fluxes to the surface decreases with the increase in integrated water vapor content in the atmosphere. This difference becomes zero when the precipitable water content in the atmosphere comes close to $50 \mathrm{~mm}$. Thus, the surface is no longer affected by longwave radiation changes due to the cloud presence. Our results also show that the longwave radiation surface air warming due to the presence of cloud cover is greatly influenced by the moisture state of the atmosphere, which nullifies the radiation effects of cloudiness in the nighttime humid tropical atmosphere.

Figure 7 shows the nighttime estimates of the July OCET $_{1}$ based on the UIUC and CCC AMIP runs. A brief comparison with empirical estimates shown in Fig. 6 reveals two major shortcomings. The CCC model provides positively biased $\mathrm{OCET}_{1}$ estimates that never cross the zero line with an increase of specific humidity. The UIUC model qualitatively resembles the empirical estimates, but the threshold, when the negative OCET $_{1}$ values in this model first appear, is shifted too much towards lower values.

\footnotetext{
${ }^{9}$ We also analyzed the relationship between the OCET 1 and surface temperature and found that the statistical relationship is basically similar to that between the $\mathrm{OCET}_{1}$ and specific humidity but is less significant than the latter. When both humidity and surface temperature were included in the regression equation for $\mathrm{OCET}_{1}$ as independent variables, we did not find any improvement because of the multicollinearity problem: absolute values of near-surface humidity and temperature are closely correlated over most of the globe, especially in humid areas.
} 


\section{Summary and conclusions}

- Statistics that characterize surface air temperature (OCET) and humidity (OCEH) interactions with cloud cover have been constructed and compared with similar statistics evaluated from the output of AMIP runs of seven GCMs. Not all GCMs reproduce these interactions properly.

- There is a general agreement in reproducing OCET in the cold season among all models tested, but large discrepancies between empirical data and some models were found for summer conditions.

- The relationship between variations of surface water vapor pressure and surface air temperature associated with cloudiness is complex. In winter, an increase in surface water vapor is associated with cloud cover and corresponds to a warmer surface. However, in summer, an increase in water vapor pressure associated with cloud cover is related to cooling at the surface.

- The OCET in daytime over all tropical regions is negative in each season. At nighttime, the sign of OCET varies with season and geographic location. During nighttime, the OCET decreases from winter to summer over monsoon regions and remains negative throughout all seasons over the humid tropical Pacific Islands.

- Over the NEL, the nighttime OCET remains positive and declines with the decrease of geographic latitude and with the change from winter to summer (in summer in polar regions, the nighttime OCET is negative because of the polar day phenomenon). Over the Tropics in winter, the nighttime OCET is positive over all tropical regions (except the western and central $\mathrm{Pa}$ cific), but in summer, over monsoon regions and in areas of permanent convection, the OCET becomes negative, while over dry tropical regions, it remains positive.

- Internally inconsistent model parameterizations (i.e., those that do not reproduce present-day relationships between climatic variables) may mislead users when applied beyond the "control" environment of the current climate; that is, when applied to climatechange studies. Therefore, a careful testing of these relationships to resolve the problems may lead to more robust models and, thus, will increase the ability of the GCMs to serve as a reliable tool for climate change studies.

The presented comparison of the GCM AMIP runs and empirical data has been gradually conducted during the past four years and characterizes the state-of-the-art of these GCMs at the time of the AMIP runs. The results (especially problems revealed during this comparison) have been conveyed to the model groups. Currently, some of these groups have significantly modified/improved their models (particularly MPI, CCC, and UIUC) and/or the cloud cover parameterization (particularly
GISS and CCC), and some of the revealed problems are therefore historical at this point in time. We strongly hope that this is the case with the most significant problem revealed during the current study: a wrong sign of summer OCET in the CCC GCM. This problem was reported three years ago to the CCC model group, and now a new version of this GCM has been released that took into account the diagnostics shown in Fig. 3 (Francis Zwiers 1998, personal communication).

Acknowledgments. We gratefully acknowledge the cooperation of the National Weather Services of the United States, Russian Federation, People's Republic of China, Norway, Sweden, Iceland, Finland, the Netherlands, France, Ireland, United Kingdom, Germany, Poland, Slovakia, Austria, and Romania for providing the data for this research. Canadian data were furnished to the U.S. National Climatic Data Center by the Atmospheric Environment Service of Canada. We also thank AMIP members from the Canadian Climate Centre; the University of Illinois at Urbana-Champaign, USA; the U.S. National Meteorological Center; the Main Geophysical Observatory, Russia; the Max Planck Institute, Germany; the Laboratoire de Météorologie Dynamique, France; and the Goddard Institute for Space Studies, USA, as well as Frank Keimig (UMass) for technical assistance. This work was supported by Grants from NOAA (NAGP0414), NSF (9501320), and DOE (98A0132).

\section{APPENDIX A}

\section{Different Methods to Assess OCE in the Data and Their Accuracy}

\section{Two different computational schemes}

From empirical data, Groisman et al. (1996) were able to evaluate associations of cloud cover with ground surface air temperature and humidity characteristics (absolute and relative humidity) for each given hour. Then, to obtain a mean daily OCE, we averaged these estimates over the 24-h period (method 1). Because the numbers of observations with clear skies varies substantially during the day and night (especially in summer months) and because we were able to mimic this procedure only when we process the CCC model output, in this paper, we used an alternative approach to evaluate the OCE on the mean daily meteorological fields (method 2). In this approach we calculated the mean daily values of these fields and cloud cover and then defined the clear-sky days as the days with mean daily cloudiness less than 0.15 . This last approach is the only one feasible when only the mean daily values of GCM runs are available (of course, the threshold 0.15 is an arbitrary value). Therefore, to be able further compare them, we have to calculate similar quantities from the data and model output. Figures A1 and A2 show a comparison of these two methods of calculation of the sensi- 

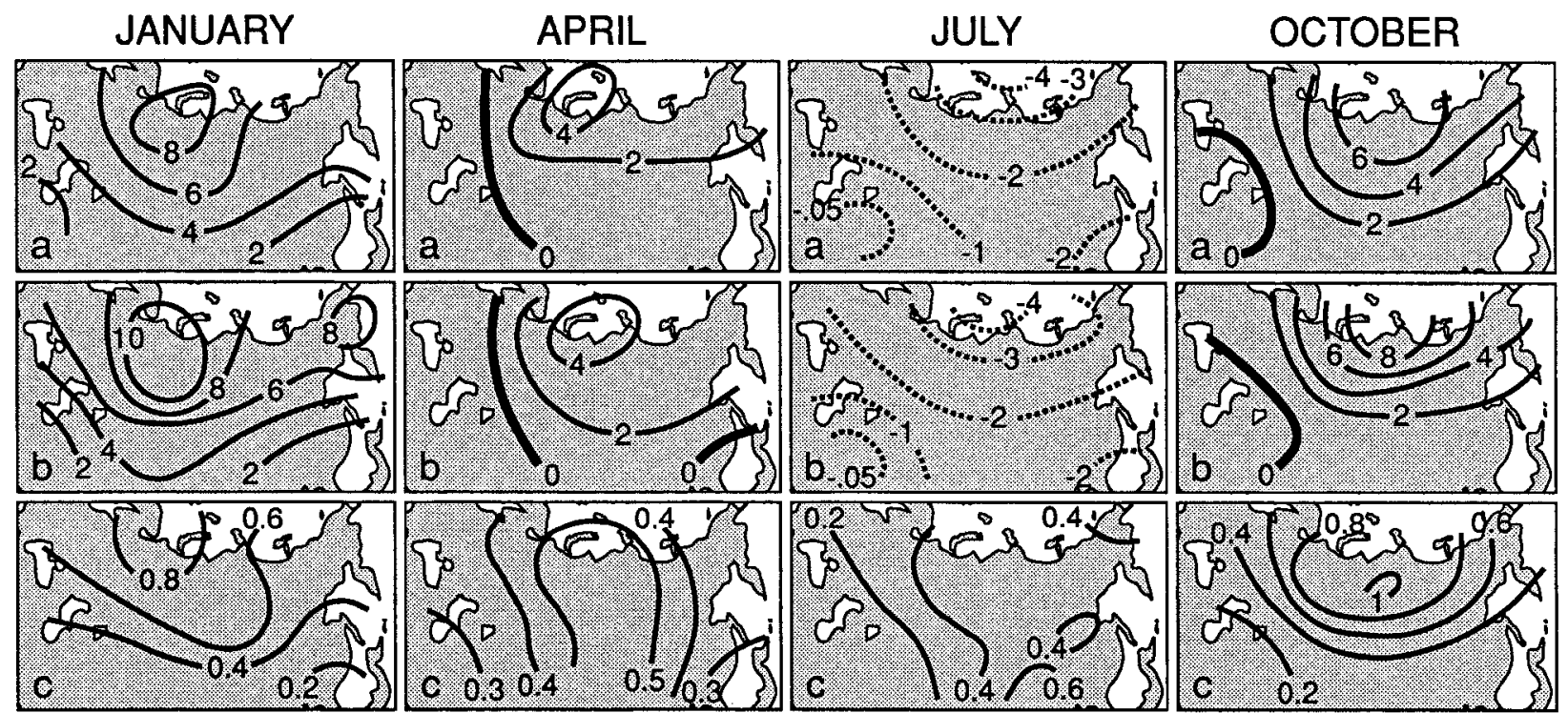

FIG. A1. Comparison of the two empirical estimates of the mean daily OCET $\left({ }^{\circ} \mathrm{C}\right)$ : (a) estimates by the first method, in which the OCET estimates were calculated for each hour in the month separately, and then the arithmetic average of the estimates was produced; (b) estimates by the second method in which mean daily and cloudiness were calculated first, and then the OCET was estimated from these mean daily values, assuming a clear-sky day as a day with cloudiness less than 0.15 ; (c) standard deviations of the OCET estimates derived by the second method.

tivity of surface air temperature and water vapor pressure to the presence of clouds for four central months in each season. In these figures, we use only the data from the former Soviet Union and Mongolia. For the calculations in method 2, standard deviations of the OCET and OCEH are also shown. These figures show that differences between these two approaches are not crucial in the further assessment of the sensitivity of surface air temperature and absolute humidity fields to the presence of clouds. The OCET and OCEH patterns in each season are very similar between method 1 and method 2, suggesting that there is no significant difference between them in assessing the overall effect of cloudiness, but there still exist non-negligible differences in their magnitudes due to the different calculation techniques. Below we summarize these discrepancies.

In winter and in transitional seasons, the positive surface air temperature differences between average and
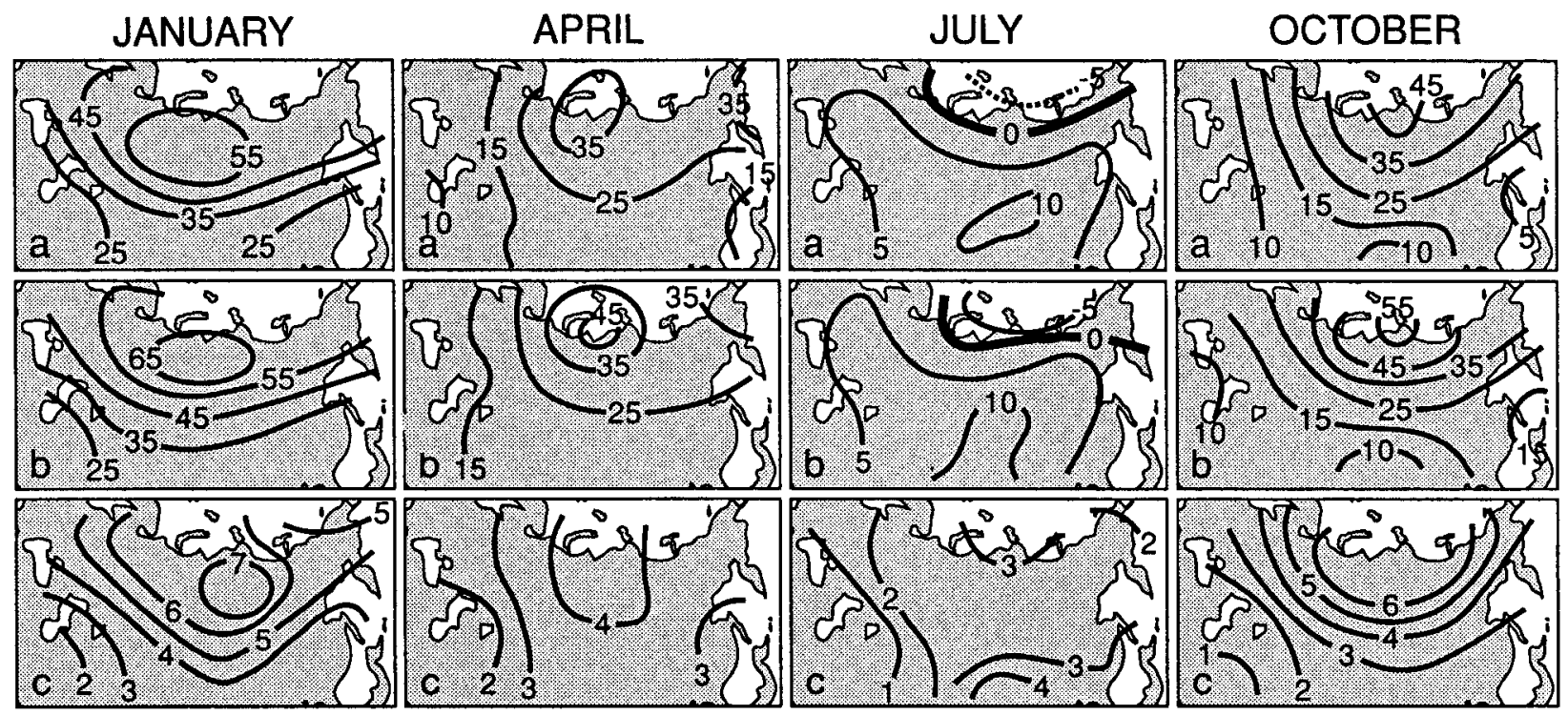

FIG. A2. The same as Fig. A1 but for the mean daily OCEH (in percent of the mean daily water vapor pressure). 
(a)

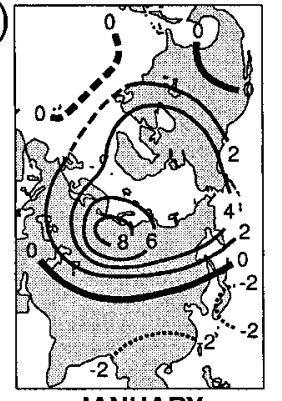

JANUARY

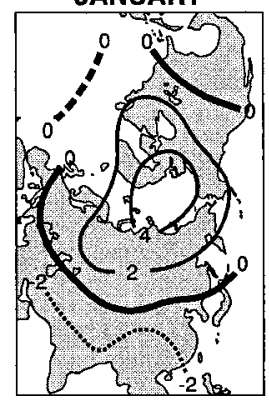

(b)
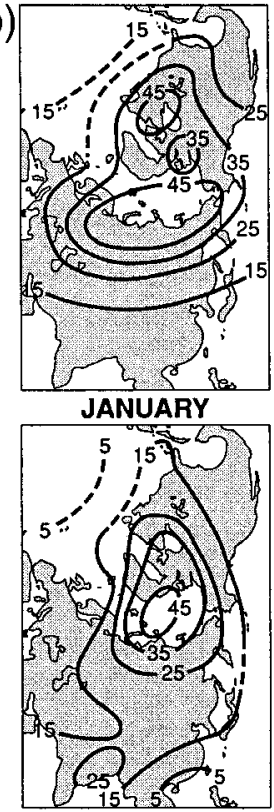

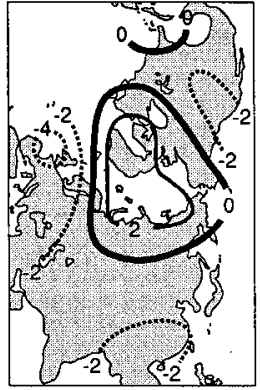

APRIL
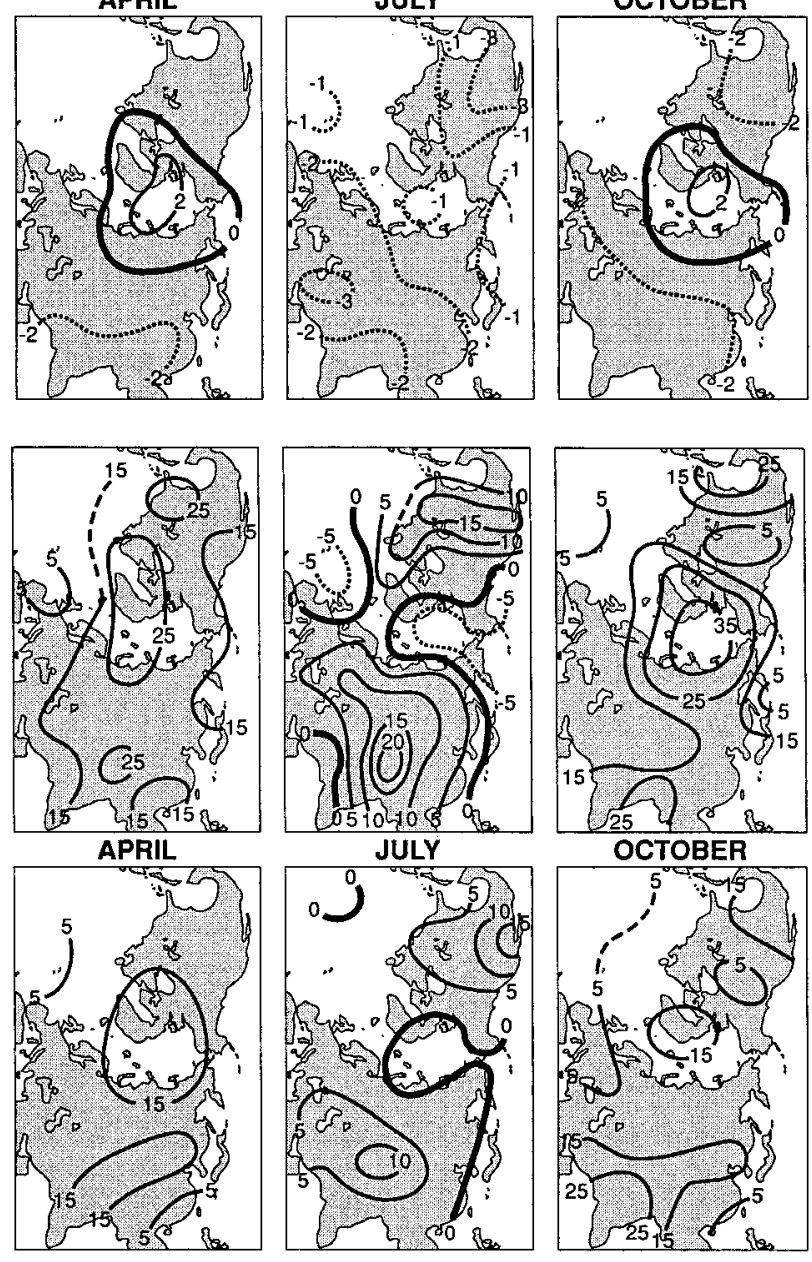

FIG. A3. Comparison of the daytime OCE (first and third rows) and $\mathrm{OCE}_{1}$ (second and fourth rows) for (a) surface air temperature $\left({ }^{\circ} \mathrm{C}\right)$ and (b) surface water vapor pressure (\%). When the mean cloud cover is far from 0.5, the magnitude of these statistics changes accordingly. Thus, in the polar region, with the mean cloud cover much higher than 0.5 , the OCE is twice as high as $\mathrm{OCE}_{1}$, while in summer, over desert regions of central Asia, the opposite is true, and the absolute values of the $\mathrm{OCE}_{1}$ exceed those of OCE.

clear sky conditions in method 2 are larger than in method 1 , and over the polar region, the difference between these two methods can reach 2-4 K. In summer, the negative OCET values produced by method 2 are smaller than in method 1, especially in high latitudes, where the difference in magnitude can reach $1-2 \mathrm{~K}$. Therefore, the cooling associated with cloudiness estimated by method 1 is not as strong as in method 2. The above shows that OCET estimates produced by method 2 are systematically biased toward positive values as compared with those obtained by method 1 . The magnitude of the OCEH patterns is larger in method 2 than in 
method 1, especially over the polar regions in winter, spring, and autumn, where it can reach $10 \%-15 \%$ of the mean absolute humidity values. The reason for the difference of the OCE between method 1 and method 2 is still not clear. The possible cause may be related to the different number of clear-sky cases during nighttime and daytime. Nevertheless, some conclusions on the OCE comparison between the empirical data and the AMIP GCM runs may need correction to some extent when the GCM outputs with the diurnal cycle resolution are available.

\section{APPENDIX B}

\section{The Use of Overcast Instead of Clear-Sky Conditions}

Following Eq. (1), Groisman et al. (1996) defined the overall cloud effect-OCE on meteorological elements, $\phi$, related to clear-sky conditions $(D)$ - as a difference between mean values of this element, $E(\phi)$, and its mean values under clear-sky conditions only, $E(\phi \mid y \in D)$. When we expanded our analyses to the humid Tropics, this definition became too restrictive because even in a 50-yr-long time series, we often were not able to secure a substantial sample size of clear-sky conditions to estimate $E(\phi \mid y \in D)$. Therefore, as a supplementary tool, we use modified statistics based on overcast conditions, $D_{1}$ :

$$
\mathrm{OCE}_{1}\left(\phi \mid y \in D_{1}\right)=E\left(\phi \mid y \in D_{1}\right)-E(\phi) .
$$

Here, we change the sign in (B1) to make it comparable with (1). Overcast conditions represent another "extreme" in cloud cover. The linearity of the substitution of (1) by (B1) is not granted, and we expected that the comparison of climatic conditions when the sky is totally obscured by cloud cover with average climate could reveal new important features of the relationship between $\phi$ and cloud cover. Generally, this does not happen. The comparison of OCE and $\mathrm{OCE}_{1}$ for surface air temperature and humidity in NEL (e.g., Fig. A3) shows that the patterns of these statistics resemble each other, and differences in magnitude in some regions can be easily attributed to the fact that mean cloud cover in these regions is closer to clear-sky conditions (summer season in the deserts of central Asia) or to overcast conditions (polar regions). We do not normalize our OCE and $\mathrm{OCE}_{1}$ estimates by the mean difference between mean cloud cover and clear/overcast conditions. This is not necessary until we can retrieve/compute from the GCMs' output the same quantities as from the observational data. But the use of $\mathrm{OCE}_{1}$ statistics becomes our best bet to properly and empirically assess the cloud effects on other meteorological elements in the humid Tropics, in polar regions with extensive stratiform cloud cover, and in any location where clear-sky conditions are rare.
TABLE C1. Standard deviations of empirical estimates of overall cloud effect (OCET and OCEH) (differences between average and clear-sky conditions) generalized for North America. (A) Surface air temperature $(\mathrm{K})$, and $(\mathrm{B})$ water vapor pressure $(\%)$.

\begin{tabular}{lcccc}
\hline \hline \multicolumn{1}{c}{ Zone } & Jan & Apr & Jul & Oct \\
\hline A. Surface air temperature $(\mathrm{K})$ & & & \\
$18^{\circ}-30^{\circ} \mathrm{N}$ & 0.28 & 0.18 & 0.13 & 0.19 \\
$30^{\circ}-40^{\circ} \mathrm{N}$ & 0.33 & 0.25 & 0.13 & 0.18 \\
$40^{\circ}-50^{\circ} \mathrm{N}$ & 0.61 & 0.43 & 0.18 & 0.28 \\
$50^{\circ}-60^{\circ} \mathrm{N}$ & 0.51 & 0.38 & 0.33 & 0.45 \\
$60^{\circ}-70^{\circ} \mathrm{N}$ & 0.45 & 0.33 & 0.33 & 0.50 \\
$70^{\circ}-80^{\circ} \mathrm{N}$ & 0.31 & 0.30 & 0.36 & 0.69 \\
& & & & \\
$18^{\circ}-80^{\circ} \mathrm{N}$ & 0.41 & 0.30 & 0.16 & 0.22 \\
$\mathrm{~B} . \mathrm{Water}^{\circ}$ & & & & \\
$18^{\circ}-30^{\circ} \mathrm{N}$ & 2.3 & 1.6 & 0.69 & 1.4 \\
$30^{\circ}-40^{\circ} \mathrm{N}$ & 2.9 & 2.1 & 0.89 & 1.4 \\
$40^{\circ}-50^{\circ} \mathrm{N}$ & 4.9 & 3.2 & 1.27 & 2.1 \\
$50^{\circ}-60^{\circ} \mathrm{N}$ & 5.3 & 2.7 & 1.98 & 3.3 \\
$60^{\circ}-70^{\circ} \mathrm{N}$ & 5.5 & 2.8 & 1.87 & 3.9 \\
$70^{\circ}-80^{\circ} \mathrm{N}$ & 4.8 & 3.4 & 2.05 & 6.2 \\
& & & & \\
$18^{\circ}-80^{\circ} \mathrm{N}$ & 3.7 & 2.4 & 1.10 & 1.7 \\
\hline
\end{tabular}

\section{APPENDIX C}

\section{Accuracy of the Empirical OCET and OCEH Estimates}

Standard deviations of empirical estimates of cloud effects (Figs. A1c and A2c) are quite small and give a general idea about the statistical significance of the revealed "overall cloud effects" on these fields. For North America, these estimates are generalized in Table C1. They are similar to those shown in the figures with the exception of the wet Tropics $\left(18^{\circ}-30^{\circ} \mathrm{N}-\right.$ Florida and Caribbean islands), where the sample size for clear skies is quite small in summer months, even when we use $40-50 \mathrm{yr}$ of observations and lenient definitions of clear skies in method 2. However, we note that the small negative values of summer OCET are nevertheless statistically significantly different from zero everywhere over northern Eurasia, and thus, the sign of this effect is well defined. The same is true for most of North America, with a prominent exception over the northeastern coastal regions of the United States and along the southern shores of the Great Lakes.

\section{REFERENCES}

Abakumova, G. M., E. M. Feigelson, V. Russak, and V. V. Stadnik, 1996: Evaluation of long-term changes in radiation, cloudiness, and surface temperature on the territory of the former Soviet Union. J. Climate, 9, 1319-1327.

Arking, A., 1991: The radiative effects of clouds and their impact on climate. Bull. Amer. Meteor. Soc., 72, 795-813.

Cess, R. D., and Coauthors, 1991: Interpretation of snow-climate feedback as produced by 17 general circulation models. Science, 253, 888-892.

— - W. L. Gates, J.-J. Morcrette, and L. Corsetti, 1992a: Comparison of general circulation models to Earth Radiation Budget Exper- 
iment data: Computation of clear-sky fluxes. J. Geophys. Res., 97 (D18), 20 421-20 426.

, E. F. Harrison, P. Minnis, B. R. Barkstrom, V. Ramanthan, and T. Y. Kwon, 1992b: Interpretation of seasonal cloud-climate interactions using Earth Radiation Budget Experiment data. $J$. Geophys. Res., 97, 7613-7617.

- , and Coauthors, 1993: Uncertainties in $\mathrm{CO}_{2}$ radiative forcing in general circulation models. Science, 262, 1252-1255.

Chanine, M. T., 1995: Observation of local cloud and moisture feedbacks over high ocean and desert surface temperatures. J. Geophys. Res., 100 (D5), 8919-8927.

Del Genio, A. D., M.-S. Yao, W. Kovari, and K. K.-W. Lo, 1996: A prognostic cloud water parameterization for global climate models. J. Climate, 9, 270-304

Gaffen, D. J., and W. P. Elliott, 1993: Column water vapor content in clear and cloudy skies. J. Climate, 6, 2278-2287.

Gates, W. L., 1992: AMIP: The Atmospheric Model Intercomparison Project. Bull. Amer. Meteor. Soc., 73, 1962-1970.

—, and Coauthors, 1999: An overview of the results of the Atmospheric Model Intercomparison Project (AMIP 1). Bull. Amer. Meteor. Soc., 80, 29-55.

GEWEX, 1990: Scientific plan for the Global Energy and Water Cycle Experiment. WMO, Geneva, Switzerland, Rep. WCRP-40 (WMO/TD 376), $83 \mathrm{pp}$

Goody, R., J. Anderson, and G. North, 1998: Testing climate models: An approach. Bull. Amer. Meteor. Soc., 79, 2541-2549.

Groisman, P. Ya., and P. M. Zhai, 1995: Climate variability under clear skies: Applications for the cloud and snow cover feedback problems. Proc. Sixth Int. Meeting on Statistical Climatology, Galway, Ireland, University College, All-Ireland Committee on Statistics, Amer. Meteor. Soc., European Union, Irish Meteorological Service, and World Meteorological Organization, 605608.

— , T. R. Karl, and R. W. Knight, 1994a: Observed impact of snow cover on the rise of continental spring temperatures. Science, 263, 198-200.

,,--- , and G. Stenchikov, 1994b: Changes of snow cover, temperature, and the radiative heat balance over the Northern Hemisphere. J. Climate, 7, 1633-1656.

—_ P.-M. Zhai, and E. L. Genikhovich, 1995: Cloud and snow cover effects on the surface-atmosphere interactions. Extended Abstracts, Papers Presented at the Joint Meeting of the Canadian Geophysical Union-Hydrology Section (CGU-HS) and International GEWEX Workshop on Cold-Season/Region Hydrometeorology, Banff, AB, Canada, GEWEX, 209-212.

— E. E. Genikhovich, and P. -M. Zhai, 1996: "Overall” cloud and snow cover effects on internal climate variables: The use of clear sky climatology. Bull. Amer. Meteor. Soc., 77, 20552065.

— — _ R. S. Bradley, and B. M. Ilyin, 1997: Assessing surfaceatmosphere interactions from former Soviet Union standard meteorological data. Part II. Cloud and snow cover effects. J. Climate, 10, 2184-2199.

Hahn, C. J., and S. G. Warren, 1999: Extended edited synoptic cloud reports from ships and land stations over the globe, 1951-1996. Data Set Documentation, NDP 026C, 77 pp. [Available from Carbon Dioxide Information and Analysis Data Center, Oak Ridge National Laboratory, Oak Ridge, TN 37831.]

— _ - and J. London, 1995: The effect of moonlight on observation of cloud cover at night, and application to cloud climatology. J. Climate, 8, 1429-1446.

Harrison, E. F., P. Minnis, B. R. Barkstrom, V. Ramanathan, R. D Cess, and G. G. Gibson, 1990: Seasonal variation of cloud radiative forcing derived from the Earth Radiation Budget Experiment. J. Geophys. Res., 95, 18 687-18 703.

Hartmann, D. L., K. J. Kowalewsky, and M. L. Michelsen, 1991 Diurnal variations of outgoing longwave radiation and albedo from ERBE scanner data. J. Climate, 4, 598-617.

Henderson-Sellers, A., 1992: Continental cloudiness changes this century. GeoJournal, 27.3, 255-262.
Higgins, R. W., K. C. Mo, and S. D. Schubert, 1996: The moisture budget of the central United States in spring as evaluated in the NCEP/NCAR and the NASA/DAO reanalyses. Mon. Wea. Rev., 124, 939-963.

Intergovernmental Panel on Climate Change (IPCC), 1990: Climate Change. The IPCC Scientific Assessment. J. T. Houghton et al., Eds., Cambridge University Press, 362 pp.

- 1996: Climate Change 1995: The Science of Climate Change. The Second IPCC Scientific Assessment. J. T. Houghton et al., Eds., Cambridge University Press, 572 pp.

Isaac, G. A., and R. A. Stuart 1996: Relationships between cloud type and amount, precipitation, and surface temperature in the Mackenzie River valley-Beaufort Sea area. J. Climate, 9, 19211941.

Kaas, E., and P. Frich, 1995: Diurnal temperature range and cloud cover in the Nordic countries: Observed trends and estimates for the future. Atmos. Res., 37, 211-228.

Phillips, T. J., 1994: A summary documentation of the AMIP models. PCMDI Rep. 18, UCRL-ID-116384, 343 pp. [Available from Program for Climate Model Diagnosis and Intercomparison, University of California, Lawrence Livermore National Laboratory, Livermore, CA 94550.]

Polyak, I. I., 1996: Computational Statistics in Climatology. Oxford University Press, $358 \mathrm{pp}$.

Potter, G. L., J. M. Slingo, J.-J. Morcrette, and L. Corsetti, 1992: Modeling perspective on cloud radiative forcing. J. Geophys. Res., 97 (D18), 20 507-20 518.

Randall, D. A., and Coauthors, 1994: Analysis of snow cover feedbacks in 14 general circulation models. J. Geophys. Res., 99 (D10), $20757-20771$.

Robock, A., C. A. Schlosser, K. Ya. Vinnikov, N. A. Speranskaya, J. K. Entin, and S. Qiu, 1998: Evaluation of AMIP soil moisture simulations. Global Planet. Change, 19, 181-208.

Rossow, W. B., and Z.-C. Zhang, 1995: Calculation of surface and top of atmosphere radiation fluxes from physical quantities based on ISCCP datasets: Part 2. Validation and first results. J. Geophys. Res., 100 (D1), 1167-1197.

Sellers, P. J., and Coauthors, 1996: The ISLSCP Initiative 1 global datasets: Surface boundary conditions and atmospheric forcings for land-atmosphere studies. Bull. Amer. Meteor. Soc., 77, 19872005.

Stephens, G. L., A. Slingo, M. Webb, and I. Wittmeyer, 1994: Observations of the earth's radiation budget in relation to atmospheric hydrology. 4: Atmospheric column radiative cooling over the world's oceans. J. Geophys. Res., 99, 18 595-18 604.

Stouffer, R. J., S. Manabe, and K. Ya. Vinnikov, 1994: Model assessment of the role of natural variability in recent global warming. Nature, 367, 634-636.

Stuart, R. A., and G. A. Isaac, 1994: A comparison of temperatureprecipitation relationships from observations and as modeled by the general circulation model of the Canadian Climate Centre. J. Climate, 7, 277-282.

Sun, B.-M., and P. Ya. Groisman, 1998: Cloud cover interaction with the near-the-surface land meteorology in the GCMs: Comparison with empirical data in Tropics and the assessment of the diurnal cycle of this interaction. Preprints, Ninth Symp. on Global Change Studies, Phoenix, AZ, Amer. Meteor. Soc., 321322

, and 2000: Cloudiness variations over the former Soviet Union. Int. J. Climatol, in press.

- R. S. Bradley, and F. Keimig, 1999: Cloud effects on the near surface air temperature: Temporal changes. Preprints, 10th Symp. on Global Change Studies, Dallas, TX, Amer. Meteor. Soc., 277-281.

,,--- , and -2000 : Temporal changes in the observed relationship between cloud cover and surface air temperature. $J$. Climate, in press.

USAFETAC, 1986: DATSAV2 Surface USAFETAC Climatic Database. User Handbook No. 4, December 1986. USAF Environ- 
mental Technical Application Center, Asheville, NC, 6 pp. + appendices. [Available from National Climatic Data Center, 151 Patton Avenue, Asheville, NC 28801.]

Weare, B. C., and I. I. Mokhov, 1995: Evaluation of total cloudiness and its variability in the Atmospheric Model Intercomparison Project. J. Climate, 8, 2224-2238.

Wielicki, B. A., R. D. Cess, M. D. King, D. A. Randall, and E. F.
Harrison, 1995: Mission to Planet Earth: Role of clouds and radiation in climate. Bull. Amer. Meteor. Soc., 76, 2125-2153.

Yao, M.-S., and A. D. Del Genio, 1999: Effects of cloud parameterization on the simulation of climate changes in the GISS GCM. J. Climate, 12, 761-779.

Zhang, M. H., R. D. Cess, and S. C. Xie, 1996: Relationship between cloud radiative forcing and sea surface temperatures over the entire tropical oceans. J. Climate, 9, 1374-1384. 